\title{
Hotspots for warm and dry summers in eastern Europe, with a focus on Romania
}

1 Viorica Nagavciuc ${ }^{1,2}$, Patrick Scholz ${ }^{1}$ and Monica Ionita ${ }^{1,3^{*}}$

$2{ }^{1}$ Alfred Wegener Institute Helmholtz Center for Polar and Marine Research, Paleoclimate Dynamics Group, Bremerhaven,

3 Germany

$4 \quad{ }^{2}$ Faculty of Forestry, Ștefan cel Mare University, Suceava, Romania

$5 \quad{ }^{3}$ Emil Racovita Institute of Speleology, Romanian Academy, Cluj-Napoca, Romania

6

7 * Correspondence:

8 Monica Ionita

9 Monica.Ionita@awi.de

Keywords: heatwaves, drought, compound events, atmospheric circulation, climate change.

\section{Abstract}

The combined effect of hot and dry extremes can have disastrous consequences for the society, economy, and the environment. While a significant number of studies have been conducted regarding the variability of the individual hot or dry extremes in Romania, the evaluation of the combined effect of these extremes (e.g. compound effect) is still lacking for this region. Thus, in this study we have assessed the spatio-temporal variability and trends of hot and dry summers in the eastern part of Europe, focusing on Romania, between 1950 and 2020and we have analyzed the relationship between the frequency of hot summers and the prevailing large-scale atmospheric circulation. The length, spatial extent and frequency of HWs in Romania has increased significantly over the last 70 years, while for the drought conditions no significant changes have been observed. The rate of increase in the frequency and spatial extent of HWs has accelerated significantly after the 1990's, while the smallest number of HWs was observed between 1970 and 1985. The hottest years, in terms of heatwave duration and frequency, were 2007, 2012, 2015, and 2019. One of the key drivers of hot summers, over our analyzed region, is the prevailing large-scale circulation, featuring an anticyclonic circulation over the central and eastern parts of Europe and enhanced atmospheric blocking activity associated with positive temperature anomalies underneath. We conclude that our scale, as well as their driving mechanisms which might lead to a better predictability of these extreme events. 


\section{Introduction}

According to the recently published AR6 report (IPCC, 2021): "It is virtually certain that there has been increases in the intensity and duration of heatwaves and the number of heatwave days at the global scale". This tendency has been clearly observed, especially over the last two decades, when a significant increase in the frequency of hot summers has been observed (Feng et al., 2020; Raymond et al., 2020; Seneviratne et al., 2012; Zscheischler et al., 2018). In some regions, these hot summers were accompanied by extremely dry conditions, leading to the development of the so-called "compound events" (Leonard et al., 2014). Overall, heatwaves and droughts fall into the category of climate related hazards which affect more and more frequently socio-economic activity, often having serious repercussions on humans and the environment (IPCC, 2021). Thus, in the context of the ongoing climate change, the study of heatwaves and droughts and the analysis of the largescale circulation patterns which favors their occurrence is of increasing interest (Feng et al., 2020; Geirinhas et al., 2021; Ionita et al., 2021a; Kong et al., 2020; Russo et al., 2019).

Several studies have suggested that due to global warming the large-scale atmospheric circulation has been altered both regionally and globally (Horton et al., 2015; Vaideanu et al., 2020). Any perturbance in the large-scale atmospheric circulation will also lead to changes in the hydroclimate, due to the fact that the atmospheric circulation plays a crucial role in the global and regional hydroclimatic variability (Ionita et al., 2020; Kingston et al., 2006, 2015; Schubert et al., 2016). Changes in temperature and precipitation have been found to be a direct response to changes in the large-scale atmospheric circulation patterns (e.g. an increase in the frequency of blocking conditions or an intensification of the westerlies) (Horton et al., 2015; Rimbu et al., 2014; Swain et al., 2016). For example, one key driver of the European hydroclimate variability is the prevalence of long-lasting high-pressure systems (also known as atmospheric blocking) (Bakke et al., 2020; Barriopedro et al., 2011; Ionita et al., 2021b; Kautz et al., 2021; Rimbu et al., 2014; Schubert et al., 2014). These long-lasting high-pressure systems have a significant impact on different types of extreme events such as heatwaves (Barriopedro et al., 2011; Della-Marta et al., 2007; Laaha et al., 2017), cold spells (Jeong et al., 2021; Rimbu et al., 2014), droughts (Ionita et al., 2012; Kingston et al., 2015; Schubert et al., 2016) and floods (Grams et al., 2014; Najibi et al., 2019). Thus it is essential to study the relationship between the changes in the magnitude and frequency of extreme events and their large-scale drivers, in order to have a better overview of the physical mechanisms leading to the occurrence of these extreme events.

In terms of exposure and vulnerability to such climate-related risks (e.g. heatwaves and droughts), Romania is particularly prone, both due to its geographical position, as well as the topographic features, which give it a very special status in relation to the manifestations of the weather (Croitoru and Piticar, 2013; Micu et al., 2021; Sfícă et al., 2017). The existence of the Black Sea and, especially, the concentric distribution (i.e. "in the amphitheater") of the Carpathian Mountains (Figure 1), induce a series of peculiarities in the prevailing climatic conditions that are also reflected in the thermal regime mediated at the scale of different regions of the country. Moreover, the evolution of the weather in Romania depends strongly on the degree of exposure to alternating, often rapid, types of air masses passing the country (e.g. continental, tropical, maritime, or polar) (Bădăluță et al., 2019; Busuioc et al., 2010, 2015; Tomozeiu et al., 2005).

At country scale, different studies have analyzed the potential changes in the frequency of HWs, either by using observational records (e.g. station data) or gridded datasets (Croitoru et al., 2016b; Croitoru and Piticar, 2013; Hustiu, 2016; Micu et al., 2021; Sfîcă et al., 2017). In their paper, Sfîcă et al. (2017) have analyzed the synoptic conditions which lead to the occurrence 
of heatwaves in Romania, over the period 1961 - 2015. By analyzing $111 \mathrm{HW}$ events they found that there are two major types of weather patterns associated with HW occurrence, namely positive or neutral sea level pressure anomalies and persistent ridges, over the analyzed region. Over the same period (i.e. 1961 - 2015), Croitoru et al. (2016) found that the frequency of heatwaves, defined based on the daily maximum temperature, shows a significant increasing trend, especially in the western and central part of Romania. Looking at a more regional scale, Croitoru and Piticar (2013) have shown that there is an increasing trend in the frequency of heatwave events over the extra-Carpathian regions of Romania (i.e. the eastern and southern part of the country) and that the daily maximum temperature is getting more extreme compared to the daily minimum temperature. Over the eastern part of the country, Hustiu (2016) has shown that the annual frequency of heatwave events features an increasing trend over the period 1961 - 2013, while in a more recent study, Micu et al. (2021) have shown that the southern part of the Carpathian Mountains is facing a significant warming trend. All the aforementioned studies are either limited in time or are very regional (Croitoru and Piticar, 2013; Hustiu, 2016; Sfícă et al., 2017; Spinoni et al., 2015) and they were mainly focused on the analysis of trends in the heatwave frequency. To our knowledge no in-depth analysis, for this region, has been made regarding the variability and trend for compound events (e.g. hot and dry summers). Moreover, taking into account that the frequency of extreme events (e.g. heatwaves, cold spells, drought, and floods) is projected to increase in the future (IPCC, 2021) it is imperative to understand the physical process forcing the increase in the frequency and magnitude of these events in order to improve their predictability. Therefore, in this study we aim to make an in-depth analysis of the spatio-temporal variability of both hot and dry summers over Romania and to analyze the relationship between the frequency of hot summers and the prevailing large-scale atmospheric circulation. The paper is focused on two main objectives: i) to analyze the trends and the spatio-temporal variability of both hot and dry summers in Romania, as well as their combined effect (e.g. compound events) and ii) to determined the large-scale circulation patterns which trigger the occurrence of hot summers over the analyzed region, by analyzing the geopotential height conditions and the frequency of atmospheric blocking during the periods characterized by a high frequency of hot days. Our study extends over the period 1951 - 2020, making it the most extensive study, from a temporal point of view, over eastern Europe. The paper is structured as follows in Section 2 we give a detailed description of the data and methods used in this study. In Section 3 we show the main results of our analysis, while the main conclusions are presented in Section 4.

\section{Data and methods}

Globally, heatwaves are recognized either by utilizing a threshold-based methodology (Perkins and Alexander, 2013) or by using the exceedance of a fixed absolute value (e.g. daily maximum temperature $>30^{\circ} \mathrm{C}$ ) (Robinson, 2001). In general, the method based on fixed thresholds takes into account periods of consecutive days when the daily maximum temperature (Tx) is above a certain percentile for a particular calendar day. In this study, we have used the 90th percentile, based on a 15-day window centered on each calendar day (Perkins and Alexander, 2013). For the duration, we have tested different lengths of $3,4,5$, and 6 consecutive days (Figure S1). The mean daily $90^{\text {th }}$ percentile was calculated over the baseline period $1971-$ 2000. The daily maximum temperature used in this study was extracted from the E-OBSv23.1e data set (Cornes et al., 2018). Here, the heatwave duration index (HWDI) is defined as the number of days per month/season when the afore-mentioned criteria were satisfied, while the number of heat waves (HW) is defined as the number of heatwaves per month/season. The temporal evolution of the HWDI for each summer month (i.e. June, July, and August) as well as for the whole summer season 
103 (JJA), for all considered lengths (Figure S1), indicate a strong interannual variability and relatively significant decadal 104 differences. As expected, the smaller the length of the threshold, the longer the heatwave. Globally, different duration 105 thresholds have been employed, depending on the analyzed regions. For example, in Canada, a duration threshold $\geq 2$ days has been used (Smoyer-Tomic et al., 2003), in Hungary and France a duration threshold $\geq 3$ days has been considered (Rey et

107 al., 2007), while in China and Ukraine a duration threshold $\geq$ 5days has been used (Chen and Li, 2017; Shevchenko et al., 108 2014). In the eastern part of Europe (e.g. Bulgaria), a duration threshold $\geq 3$ days has been found useful (Gocheva et al., 2006).

109 Since Romania is situated in the eastern part of Europe, where a threshold $\geq 5$ or 6 days has been tested and because we want 110 to analyze extreme heatwave in this study, the rest of the analysis is focused on a threshold $\geq 5$ days.

111 The hydroclimatic conditions, with a special focus on the drouth component (values $<-1$ ), are defined by considering the 1112 month and 3-month Standardized Precipitation Index (SPI3) (McKee et al., 1993). For this analysis, we used the June, July, 113 and August SPI1 index and the August SPI3 index, which integrates the drought conditions over the whole summer months 114 (i.e. June-July-August). The SPI index was extracted from the E-OBS v23.0e data set, with a spatial resolution of $0.1^{\circ} \mathrm{x} 0.1^{\circ}$ 115 and a temporal resolution covering the period 1950 - 2020. SPI is based on the accumulated precipitation data, where the 116 precipitation (PP) data is fitted to a gamma distribution (McKee et al., 1993). The advantage of using SPI is that it is 117 standardized on a given period and a predefined distribution. Therefore, each SPI value corresponds to a predefined 118 probability. Here, we choose the threshold of -1 meaning that all occurrences of SPI below the threshold would be considered 119 as drought. This threshold generally corresponds to a moderate to extreme drought event. Taking into account our definition 120 HW and drought, a compound hot and dry (CHD) event is defined as a combined index when a heat wave episode occurs 121 during a period of drought conditions (i.e. a summer with an associated 3 month SPI value (SPI3 August) <-1). This definition 122 has also been used successfully for other regions (Geirinhas et al., 2021; Ionita et al., 2021a; Russo et al., 2019). For our analysis, we only use the grid points that meet the criteria for compound events.

124 To compute the SPI, HWDI, and CHD we make use also of a regional dataset covering Romania, namely the ROCADA data set (Dumitrescu and Birsan, 2015). ROCADA is a daily gridded observational data set for minimum, mean and maximum temperature, precipitation, soil temperature, sea level pressure, relative humidity, cloud cover, and sunshine duration, covering Romania, based on station information. The data set covers the period 1961-2013 and the spatial resolution of the dataset is $0.1^{\circ} \times 0.1^{\circ}$. Because the ROCADA data sets have a lower temporal extent compared to the EOBS data set, most of the analyses in this study are based on the EOBS dataset. A detailed comparison between the EOBS and ROCADA dataset is given throughout the manuscript.

To analyze the large-scale driving mechanism of heatwaves, we use the daily temperature at $850 \mathrm{mb}$ level (TT850), the daily geopotential height at 500mb level (Z500), as well as the daily zonal and meridional wind at 500mb level. These datasets have

133 been extracted from the ERA5 reanalysis project (Hersbach et al., 2020), and have a spatial resolution of $0.25^{\circ} \times 0.25^{\circ}$, 134 covering the 1950-2020 period. 
137

138

139

140

141

142

143

144

145

146

147

148

\section{Results}

\subsection{Summer heat waves in eastern Europe: variability and trends}

The heatwave duration index (HWDI) averaged at the country level and the fraction of the country affected by the heatwave (AREA) are shown in Figure 2. This figure reveals that there is strong interannual and decadal variability throughout all summer months (Figure 2- left column). For June, there is a statistically significant increase in both HWDI (Figure 2a and Table S1) and AREA (Figure 2b), which is a much higher frequency of both after the beginning of the 1990's. The longest heatwave was recorded in June 2019 and lasted 10 days, when more than $90 \%$ of the country was affected. Until the beginning of the 1990's there were relatively few HWs, most o them observed between 1960 and 1970, but their duration is much smaller compared to the events recorded from 2000 onwards. Also in terms of the affected area, after 1990's most of the heatwaves had a larger spatial extent, with an area covered by a HW of more than 80\% in 1996, 2002, 2003, 2010, 2012, and 2019, respectively.

As in the case of June, for July we observe also a statistically significant increase both in the HWDI (Figure 2c and Table S1) and the AREA (Figure 2d). At the beginning of the analyzed period (i.e. 1950 - 1960), there were heatwave events lasting on average $4-5$ days (when averaged at country level) and covering an area up to 80\%. Between 1970 and 1985 no HWs were recorded throughout the country. After 1985 there is a steep increase in the duration of the HWs, with the longest HWs in July 2007 and 2012, when the whole country was affected (i.e. AREA = 100\%). Years 1987, 2002, 2007, 2012, and 2015 have been characterized by HWs with a spatial coverage of more than $80 \%$ (Figure $2 \mathrm{~d}$ ). For August, the temporal evolution of HWDI (Figure 2e) and AREA (Figure 2f) follows the same path as June and July, meaning a significantly increasing trend in both the duration (Table S1) and area (not shown) after 1995. Over the period 1964 - 1988 no HWs has been recorded in August, while most of the longest and extended HWs were recorded in the last two decades of the analyzed period. The longest HW recorded in August was in 2015, followed by 2012, 1992, and 1952. In 1992, 2012, and 2015 the area covered by HWs was higher than $90 \%$ (Figure 2f). For all analyzed months, the HWs recorded in the last two centuries were both longer and had a higher spatial extent. If we analyzed the whole summer months have taken together (JJA), we have a very clear picture (Figure 2g and 2h): the period 1950 - 1970 was characterized by the occurrence of HWs with an average duration of 10 days and a spatial extent between 20\% up to 80\%, followed by a relatively HW free period between 1970 and 1985 . After this period there was a significant increase in the duration of the HWs and most of them reached a spatial extent of more than 50\%, especially over the last decades (i.e. 2001 - 2020). In terms of used data sets, both EOBS and ROCADA datasets capture in a similar manner the temporal distribution of the HWDI and AREA. The correlation coefficients between the monthly HWDI (AREA), computed based on the two datasets (i.e. E-OBS and ROCADA), is $>0.9$ for all months, thus the EOBS dataset is able to fully capture the spatio-temporal variability of the HWs, allowing us to extend our analysis for 70 years. This finding is supported also by other studies which have used the EOBS data set for regional analysis over Romania (e.g. Ionita et al., 2015; Sidău et al., 2021). For example in their study, Sidău et al. (2021) have shown that the EOBS data set captures the best, when compared to observations, the local variability, in terms of temperature and precipitation, over Romania.

Since the number of HWs per year is small, especially in the first analyzed period (i.e. 1951 - 1985), we have aggregated the number of heatwaves in decades, to be able to analyze the spatio-temporal changes in their occurrence. We have performed 
the decadal analysis for each summer month separately (Figure S2, S3, and S4) and for the whole summer season (JJA) as a whole (Figure 3). We focused our analysis in his way, to have an equal number of months/decade and also to provide decadal evolution of HWs hotspot, at country level. The first analyzed decade is $1951-1960$, followed by $1961-1970$, and so on until 2011 - 2020. Figure 3 shows that the geographical distribution of the number of HWs/decade summed over the summer months. Overall, there is an increased variability among different regions of the country depending on the analyzed decades. Over the decade 1951 - 1960 up to $24 \mathrm{HWs}$ /decade have been recorded in the south-eastern part of the country (i.e. the Dobrogea region), while in the north-west part of the country up to $10 \mathrm{HWs} /$ decade have been recorded (Figure 3a). Over the decade 1961 - 1970 HWs (up to 8 HWs/decade) have been recorded mainly in the Intra-Carpathian region (i.e. the north-west part of the country) (Figure 3b). The decade 1971 - 1980 was almost HWs free (Figure 3c), while for the decade 1981 - 1990 there were less than $2 \mathrm{HWs}$ /decade at country level (Figure3d). Starting with the decade $1991-2000$ the number of summer HWs started to increase all over the country (Figure 3e). During the $2001-2010$ decade, the HW hotspots developed in the western part of the country and the Doborgea region (i.e. south-eastern part of the country) (Figure 3f). Over the decade 2011 - 2020, there were up to $24 \mathrm{HWs/decade,} \mathrm{the} \mathrm{most} \mathrm{affected} \mathrm{areas} \mathrm{being} \mathrm{the} \mathrm{north-western} \mathrm{part,} \mathrm{inside} \mathrm{the} \mathrm{Carpathian} \mathrm{Chain,}$ and the south-eastern part of the country (Figure 3g). Overall, there was up to 6 times more HWs in the last decade compared to the HWs at the beginning of the analyzed period.

When looking at the decadal distribution of HWs hotspots for each summer month separately, there are some clear differences, especially at the beginning of the analyzed period (Figure S2, S3, and S4). Over the decade 1951 - 1960, there were up to 5 HWs/decade in July (Figure S3a) and August (Figure S4a), focused in the north-western part of the country and the most south-eastern corner of the country. In June, a limited number of HWs have been recorded in this decade ( 2 HWs/decade) over the eastern part of the country (Figure s2a). The decade 1961 - 1970 was characterized by up to 4 HWs/decade in June, over the north and north-western part of the country (Figure S2b), while in July (Figure S3b) and August (Figure S4b) 1 HW/decade was recorded in the western part of the country. The decade 1971 - 1980 was HW free in July (Figure 3c) and August (Figure 4c), while in June there were $~ 1$ HW/decade over a small part of the country (Figure S2c). The decade 1981 - 1990 was characterized by up to $2 \mathrm{HWs}$ /decade, at country level, in July (Figure S3d) and August (Figure S4d). Starting with the 1991 - 2000 decade, the number of HWs/decade starts to increase at the country level, the most affected months being June (Figure S2e - 2g) and August (Figure S4e - 4g). Over the decade $2001-2010$ there were up to 7 HWs/decade recorded in the south and south-eastern part of the country in June (Figure S2f), up to $6 \mathrm{HWs}$ /decade in the western part of the country and the Dobrogea region, in July (Figure S3f) and up to $10 \mathrm{HWs} /$ decade in August, with a focus on the Dobrogea region (Figure S4f). For the last decade (i.e. 2011 - 2020) the number of HWs/decade has increased in all months, but their spatial distribution differs. In June (Figure S2g), the highest number of HWs/decade was recorded over the north-western part of the country (up to $10 \mathrm{HWs} /$ decade) and in Doborgea region. In July, the HWs hotspots are over the northern and eastern part of the country (Figure S3g), while in August there is a homogenous distribution of up to 10HWs/decade, throughout the country (Figure S4g).

From the decadal analysis of the number of HWs, we can clearly state that the decade 2011 - 2020 was characterized by a significant increase in the number of HWs compared to the previous decade, this increase being the strongest in August. There are preferred hotspots for the HWs occurrence, depending on the analyzed decade and month, these hotspots being strongly influenced by the geographical distribution of the Carpathian Mountains. The most affected regions by the HW occurrence 
210 are the north and north-western part of the country and the Dobrogea region. Dobrogea region is a region which has been

211 subjected to a significant increase in the mean air temperature and a significant decrease in the summer precipitation (Chelcea

212 et al., 2015; Prăvălie et al., 2017). Overall, there is a significant increase, of $\sim 0.2 \mathrm{HW}$ /decade in June, over most parts of the country, except some small regions in the north-eastern part (Figure 4a). In July a significant increase of $\sim 0.1 \mathrm{HWs} / \mathrm{decade}$ can be observed in the northern part of the country, while for the rest of the country no significant changes have been recorded (Figure 4b). In August, there is a significant increase in the number of HWs over the analyzed region, especially over the eastern part of the country ( $0.2 \mathrm{HWs} /$ decade). When we consider all summer months together, the increase in the number of HWs is significant at the country level, with an increase of up to $0.4 \mathrm{HW}$ s/decade in the eastern part of the country.

\subsection{Summer droughts in eastern Europe: variability and trends}

Since the aim of this study is to analyze both warm and dry summer in the eastern part of Europe, in this section we evaluate the changes in the occurrence of drought conditions. The drought conditions are analyzed by employing the standardized precipitation index with a 1-month accumulation period to represent the drought conditions at monthly scale (i.e. SPI1 June, SPI1 July, and SPI1 August) and with a 3-month accumulation period to analyze the drought conditions over the whole summer (i.e. SPI3 August). To analyze the variability and trends of drought conditions, at the country level, we performed the same analysis like in the previous section: we averaged the SPI at the country level (Figure 5), we performed also the decadal analysis (Figure 6), and the trend analysis (Figure 7). The temporal evolution of June SPI1 (Figure 5a), July SPI1 (Figure 5c), August SPI1 (Figure 5e), and August SPI3 (Figure 5g) indicates a strong interannual variability of drought conditions, at the country level, and no significant drying or wetting trend. For June, the driest years, both in terms of amplitude (Figure 5a) and spatial coverage (AREA, Figure 5b) were: 1950, 1968, 2000, and 2002. In 2002 the whole country was affected by drought, this summer being of the driest summers on record for Romania (Ionita et al., 2016). For July, the driest years were: 1952, 1956, 1989, and 2015 (Figure 5c), respectively. For these years, the drought conditions extended to more than $60 \%$ of the country (Figure 5d). In August, the driest years, at the country level were recorded in 1952, 2000, 2002, and 2018 (Figure 5e), with the drought conditions covering more than $60 \%$ of the country (Figure 5f). August SPI3, which is an indicator of drought conditions over the whole summer, indicates that the driest summer, over the eastern part of Europe, were: 1950, 1952, 2000, 2002, and 2018, respectively (Figure 5g). For all these summers, the drought was covering more than $60 \%$ of the country (Figure $5 \mathrm{~h}$ ).

The drought hotspots, at a decadal scale (Figure 6), indicate strong spatio-temporal variability between the different analyzed decades and between different regions of the country. Over the 1951 - 1960 decade (Figure 6a), the drought hotspots (defined as the number of months/decade when SPI <-1 for each grid point) was focused in the north-eastern part of the country (Figure $6 a)$. For this period, there were up to 6 summers/decade characterized by drought conditions over these regions. For the decade 1961 - 1970 (Figure 6b) and 1971 - 1980 (Figure 6c) there were a relatively limited number of dry summers ( 2 dry summers/decade) throughout the country, mostly focused on the north-western part and south-eastern part. For the decade 1981 - 1990 (Figure 6d), there is a rather homogenous pattern at the country level, with up to 3 dry summers/decade affecting the whole country. The decade $1991-2000$ (Figure 6e) indicates a hotspot for drought in the northern part of the country ( 6 dry summers/decade), while for the rest of the country there were up to 2 dry summers/decade. The decade 2001 - 2010 is 

temporal evolution of the drought conditions (Figure 6) indicates that drought are not homogenous throughout the country and that the decades with the highest number of dry summers were 1951 - 1960 (over the eastern part of the country) and 1991 - 2000 (over the northern part of the country). A similar inhomogeneous pattern is observed when looking at the SPI trends, both at monthly (Figure 7a-c) and seasonal time scale (Figure 7d). Overall, in June there is a non-significant wetting trend over the central and north-eastern part of the country and a non-significant drying trend over the northern and southern part of the country, and Doborgea region (Figure 7a and Table S2). In July there is an overall wetting trend at the country level, with small exceptions in the northern most part of the country, but the wetting trend is significant only over small areas in the eastern part of the country (Figure 7b). In August, the spatial trend pattern is rather distinct compared to June and July, the northern half and the eastern part of the country being characterized by a drying trend, while for the rest of the country there is no clear signal (Figure 7c). August SPI3 trend, which takes into account all summer months, follows the features identified for each month analyzed separately: a drying trend over the northern most part of the country and in the northern part of Doborgea, and a wetting trend over the rest of the country (Figure 7d). The inhomogeneous spatial distribution for SPI1 and SPI3 (Figure 6 and 7) indicate that drought conditions in Romania are very divers, from a spatial point of view, over the analyzed period. This finding is in agreement with previous studies which have shown that there is no spatial consistency in the occurrence of droughts, based on the SPI, over Romania (Cheval et al., 2014; Ionita et al., 2016) and also at European level (Ionita and Nagavciuc, 2021; Vicente-Serrano et al., 2021).

\subsection{Historical evolution of compound events (e.g. warm and dry summers) in eastern Europe}

Over different regions of the world, hot summers are usually accompanied by extremely dry conditions, leading to the development of the so-called "compound events" (Feng et al., 2020; Geirinhas et al., 2021; Leonard et al., 2014; Ridder et al., 2020; Russo et al., 2019). These compound events have the tendency to occur at the same time or in sequence, leading to devastating consequences for the society, economy, and environment (Raymond et al., 2020; Zscheischler and Seneviratne, 2017). In this sub-section, we analyze the spatial distribution and the decadal variability of such compound events (i.e. hot and dry summers), over the period 1951 - 2020. In a first step, in Figure 8 we have computed the total number of HWs (Figure 8 - left column), the total number of months when the SPI < -1 (indicating dry months) (Figure 8 - middle column), and the total number of months when we had both hot (e.g. a grid point was characterized by a HW) and dry conditions (e.g. a grid point was recoding SPI values < -1) (Figure 8 - right column). The analysis was performed over the whole period $1951-2020$ and for June (Figure 8a - 8c), July (Figure 8d - 8f), August (Figure 8g - 8i), and JJA (Figure 8j - 8e). From a climatological point of view, in June, HWs have a tendency to occur mostly in the western part of the country, while dry conditions tend to occur over low altitude regions (Figure 8a). Over the Carpathian Mountains, the number of dry years is much smaller compared to the region located at low altitudes (Figure $8 \mathrm{~b}$ ). When looking at the combined effect of hot and dry summers (CHDs) (Figure 8c), we observed that these compound events, in June, tend to occur in the western part of the country (following the climatology of HWs) as well as in the south and south-eastern part of the country (following the climatology of droughts). In July, HWs tend to occur mostly in the western part of the country, as well as in Dobrogea region (Figure 8d), while dry years tend to occur mainly on a longitudinal band, in the central part of the country from south to north (Figure 8e). The CHDs, in July, follow again the same spatial distribution as the ones of the HWs, with the highest number of CHDs being recorder in the western and northern part of the country (Figure 8f). In August, HWs tend to occur at country scale (Figure 
$8 \mathrm{~g}$ ) with the highest number in the south-western part of the country, the Dobrogea region and the eastern part of the country ( $\sim 30 \mathrm{HWs} / 70$ years). The drought conditions are distributed all over the country, with small exception in the northern part, where the frequency of dry years is much smaller compared to the rest of the country (Figure 8h). The frequency of CHDs, in August, is mainly focalized in the southern part of the county, with the highest amplitudes ( $\sim$ CHDs/70 years) in the southwestern and south-eastern part (Figure 8i). When analyzing the whole summer months together, a very clear pattern emerges in the case of HWs: the most affected area, thought the whole summer is the western part of the country and the Dobrogea region ( $70 \mathrm{HWs} / 70$ years) (Figure 8j). In summer, drought conditions tend to focus in the northern part of the country and over smaller areas in the south-eastern part of the country (Figure 8k). As a consequence, most of the CHDs, have occurred mainly in the western and central part of the country (Figure 8e), over the last 70 years ( 12 CHDs / 70 years).

Looking at decadal time scale, and summing over the whole summer months (i.e. June, July, and August) over the period 1951 - 1960, CHD events occurred throughout the whole country with small exceptions in the south-eastern part (Figure 9a). Over the decade 1961 - 1970 the frequency of CHDs was smaller compared to the previous decade as well as their spatial extent (Figure 9b). The decade 1971 - 1980 was CHD free (Figure 9c), while over the decade 1981 - 1990 there were up to 3 CHDs over a small region in the southern part of the country and 1 CHD at the country level (Figure 9d). Over the decade 1991 - 2000, the CHD events were more frequent (up to 4 CHDs/decade) especially in the northern part of the country (Figure 9e). Throughout the decade $2001-2010$ (Figure 9f) at least $1 \mathrm{CHD} /$ decade was recorded over most of the country, with small exceptions in the eastern part, where no CHD was recorded. Compared with the previous decades, the period $2011-2020$ (Figure $9 \mathrm{~g}$ ) is characterized by a more homogenous pattern, with CHDs occurring all over the country. The highest number of CHDs ( $\sim 3$ CHDs/decade) was recorded in the northern regions (Figure 9g). Because the SPI has a very inhomogeneous spatial pattern, making it rather difficult to match the regions where also HWs occur, the number of CHDs is relatively small at the country level, and no clear trend has been observed in their frequency (not shown).

The analysis of the temporal variability of the HWDI and AREA (Figure 2) has emphasized some extreme HWs for each analyzed month, both in terms of duration and coverage. Thus, in this sub-section, we make a detailed analysis for the longest HW for each month, in terms of extremeness (e.g. rank maps) and large-scale driving factors. The analysis is focused on three distinct cases: July 2012, August 2015, and June 2019, respectively. July 2012 was marked by persistent heat waves, which have determined extremely high temperatures at the beginning of the month in the western part of the country, afterwards extending to all regions, but especially in the plain and plateau areas (Figure 10a). In some regions of the country (e.g. eastern and central part) the duration of the HWs was up to 24 days. In terms of drought, most of the country was affected by moderate to extreme drought in July 2012 (Figure 10b), with small exceptions in the western part of the country. July 2012, was the hottest month on record (e.g. over the period 1950 - 2020) over most of the country (Figure 10c). In July 2012, 114 meteorological stations through the country recorded temperatures above $35^{\circ} \mathrm{C}$ (Dima et al., 2016). Over the central part of the country, from the south to the north, July 2012 was both hot and dry (Figure 10d). The peak of the heatwaves was recorded in the last week of the month (Figure S5). Starting with the $23^{\text {rd }}$ of July, the atmospheric circulation was characterized by a south-easterly flow, which led to an advection of tropical air masses, generated over the Arabian Peninsula and extending to Russia (Figure S6). At the country level, this large-scale atmospheric 

temperatures $>35^{\circ} \mathrm{C}$ ), especially in the southern and eastern regions (Figure 10e and S5). Between the $26^{\text {th }}$ and $29^{\text {th }}$ of July 2012 , the daily maximum temperature up to $10^{\circ} \mathrm{C}$ was higher, compared to climatology, especially in the eastern part of the country (Figure S6d - S6g). These excessive temperatures were driven by the persistence of a high pressure system over the eastern part of Romania and the presence of an atmospheric blocking center over the western part of Russia (contour lines in Figure S6).

The heat wave and drought event observed throughout the summer of 2015, affected a large portion of continental Europe and was one of the most severe dry and hot summers over the observational period (Ionita et al., 2017; Laaha et al., 2017; Van Lanen et al., 2016). Record high temperatures were observed throughout the whole summer over different parts of Europe. Extremely high temperatures already started to be recorded in June 2015 over the Iberian Peninsula, central and eastern France, the western Alps, and Ukraine. The heatwave and drought conditions extended towards the central part of Europe in July 2015 (Ionita et al., 2017). By August 2015, the heat wave moved and continued to develop in central and eastern Europe, including Romania. For most of the month of August 2015, Romania was under the influence of extremely high temperatures. The first heat waves occurred between the $3^{\text {rd }}$ and $16^{\text {th }}$ of June (not shown). Between the $17^{\text {th }}$ and $23^{\text {rd }}$ of August, a short relief was observed, with temperatures below the climatological mean (not shown). The second and most intense heat waves (e.g. in terms of the temperature anomalies) started to develop on the $24^{\text {th }}$ of August reaching it's peak at the end of the month (Figure S7). The longest heat wave was recorded over the northern and eastern parts of the country (Figure 11a). In some regions in the eastern part of the country, there were up to 24 days which fulfilled the HW definition. Overall, the drought conditions in August 2015, were not as intense as in July 2012. Only the northern part of the country experienced both heat wave and drought at the same time (Figure 11b and 11d). August 2015, was also the hottest month on record (e.g. over the period 1950 - 2020) in the northern and north-eastern part of the country (Figure 11c). The extremely high temperatures recorded, especially in the last week of August 2015 were mainly driven by the prevailing large-scale circulation. The two long-lasting heatwaves in August 2015 were determined by the extension of the North African ridge over most of the European continent (Figure 11e and Figure S8). During the peak of the second heatwave (i.e. 28.08 - 31.08.2015) the eastern part of Europe was affected by a persistent atmospheric blocking system (contour lines in Figure S8), which was centered over

344 Romania. This persistent blocking system led to the advection of hot and dry air from the south. Moreover, the anomalous 345 Z500 center over the eastern part of Europe (Figure 11e and S8) suggests a dominant subsidence and adiabatic warming, reduced cloudiness, and increased incoming solar radiation, thus leading to excessive temperatures over the affected regions. 2f). According to Copernicus (https://climate.copernicus.eu/surface-air-temperature-june-2019) June 2019 was the hottest June on record both globally and for Europe, with the central and eastern Europe particularly warm throughout the whole month. In June 2019, the north-western and south-eastern parts of Romania were the most affected regions by extreme temperatures (Figure 12a and 12c). Record breaking temperatures were recorded in the most northern part of the country as well as in the Dobrogea region (Figure 12c). These record breaking temperatures were corroborated with drought conditions (Figure 12b and 12d). The eastern, central, and south-western parts of the country were less affected by extreme temperatures (Figure 12a and 12c) and these regions were characterized by wet conditions throughout the month (Figure 12b). The 
The atmospheric circulation at the peak of the heatwave event (Figure S9 and S10) was characterized by a persistent wavelike pattern extending from the North Atlantic Ocean towards Eurasia (Figure 12e and S10). Positive (negative) geopotential anomalies were observed over eastern Europe (central North Atlantic and central Siberia) corresponding to the local positive (negative) temperature anomalies underneath (Figure 12e and S9). The spatial structure of the Z500 field resembles the classic omega blocking circulation (Figure S10 - contour lines). This pattern favors the advection of warm air from the Sahel towards the eastern part of Europe and enhances the incoming solar radiation, leading to extremely high temperature anomalies underneath the high pressure system.

All analyzed extreme HWs in this section were mainly driven by the presence of a high-pressure system over the analyzed region, during the peak of the HW event. In order to identify if the presence of a persistent high pressure system is a necessary ingredient for all HWs identified throughout the period 1950 - 2020, we have computed the composite maps (See Supplementary file for the composite maps definition) for the years when the HWDI index (Figure 2 - left column) was $>5$ days and the corresponding Z500 anomalies and the corresponding wind vectors. We performed the analysis for each month separately (Figure S11). Due to the fact that the relationship between the large-scale atmospheric circulation and the European hydroclimate was found to be limited due to non-stationarity issues (Ionita et al., 2020; Rimbu et al., 2004; Vicente-Serrano and López-Moreno, 2008), we have computed also the stability map s between the HWDI and the monthly Z500. The aim of the composite map analysis is to analyze the relationship between the HWDI and the large-scale atmospheric patterns, but this methodology does not consider if the relationship between the two variables is stationary in time or not. In order to overcome the problem of non-stationarity and to test if the identified relationship between the HDWI and Z500 is stable over time, we employed a methodology, namely the stability maps, used for the monthly to seasonal prediction of the mean runoff of the Elbe River and in dendroclimatological studies (Ionita et al., 2015a; Nagavciuc et al., 2019). A detailed description of this methodology is given in the aforementioned papers.

The June composite map of Z500 anomalies and the corresponding wind vectors for years with HWs lasting more than 5 days, is characterized by positive Z500 anomalies over the central and eastern part of Europe and negative Z500 anomalies over the central North Atlantic Ocean (Figure S11a). Moreover, HWs in June, in Romania, are also associated with an increase in the number of atmospheric blocking days, centered over the south-eastern part of Europe (Figure S12a). The spatial structure of the Z500 anomalies, centered over the eastern part of Europe, leads to the advection of hot and dry air from the south or southeastern part of Europe. The large-scale atmospheric circulation associated with HWs over Romania, in July, is similar with the spatial structure identified in June, both in the Z500 field (Figure S10b) as well as in the case of 2D atmospheric blocking (Figure S12b). In August, the spatial structure of the Z500 field, associated with the occurrence of HWs over Romania, is characterized by a wave-train like pattern of alternating Z500 anomalies, which extends from the eastern part of the U.S until Eurasia (Figure S11c). Extreme HWs, in August, are associated with a low pressure system over the eastern part of the U.S., followed by positive Z500 anomalies over the western part of the central North Atlantic Ocean, negative Z500 anomalies centered over the British Isles, and positive Z500 anomalies over the central and eastern parts of Europe. This wave-like pattern suggests a stationary Rossby wave pattern, which is usually associated with heatwaves and droughts over the Eurasian continent (Bakke et al., 2020; Barriopedro et al., 2011; Ionita et al., 2012; Schubert et al., 2014). As in the case of June and July, HWs in August are also associated with an increased frequency of atmospheric blocking over the eastern part of Europe 
confirmed by the stability maps. June HWDI is stably and positively correlated with June Z500 over the eastern part of Europe, centered over Romania (Figure 13a). The same pattern can be observed also when we compute the stability map between July HWDI and July z500 (Figure 13c). In the case of August, the HWDI is stable and positively correlated with Z500 over a region extended from the North Atlantic basin towards central and eastern part of Europe and negatively correlated with Z500 centered over the British isles and North Sea (Figure 13e). This dipole-structure is reminiscent of the East Atlantic teleconnection pattern, which was found to have a significant influence on the variability of temperature and precipitation over Europe, throughout the whole year (Gao et al., 2017). Based on the monthly stability maps identified in Figure 13, we defined a Z500 index averaged over the stable regions (black squares in Figures 13a, 13c, and 13e) to analyze the interannual variability of the Z500 over this regions in a long-term context. This analysis was motivated by the fact that it has been suggested that the Z500 over central and western part of Europe has increased recently leading to an increase in the frequency of HWs over these regions (Porebska and Zdunek, 2013; Tomczyk and Bednorz, 2016). June Z500 index exhibits strong interannual variability over the last 70 years, with the highest amplitudes since the beginning of 1990s (Figure 13b). Notably, the highest value of this index was recorded in 2019, which is also the month with the longest June heatwave (Figure 2a). Over the period 1990 - 2020 there is a significant increasing trend in the June Z500 averaged over the eastern part of Europe, a trend which closely resembles the one observed for the June HWDI (Figure 2a). The results of the trend analysis for each month and each analyzed period are given in Table S3. As in the case of June, July Z500 index exhibits also strong interannual variability over the last 70 years and a significant increasing trend over since 1990's onward (Figure 13d). The highest values of this index were recorded in 1954,1987, 1988, 2007, 2012 and 2015, respectively. July 2012 is also the month with the longest July heatwave over the analyzed period (Figure 2c). The time series of August Z500 index exhibits also strong interannual variability over the last 70 years and a significant increasing trend over the period 1990 - 2020 (Figure 13f). The highest value of this index was recorded in 1952, 1962, 1992, 2010, 2015, 2017 and 2019, respectively. August 2015 is also the month with the longest July heatwave (Figure 2c). Overall, the time series of the monthly Z500 presents a strong interannual variability and a significantly increasing trend starting with the beginning of the 1990's, which mirrors the trends observed in the monthly HWDI (Figure 2). For July and August, the trend of the Z500 indices is significant for both analyzed periods (i.e. 1950 - 200 and 1990 - 2020), while for June the trend is significant only when we consider the 1990 - 2020 period (Table S3).

\section{Conclusions}

One of the main conclusions of the recently published IPCC AR6 report (IPCC, 2021) was that "future heatwaves will last longer and have higher temperatures". In this report (and the references therein) it has been shown that on a global scale there is clear evidence of an increase in the number of warm nights and days and a decrease in the number of cold nights and days (IPCC, 2021). Overall, the frequency of warm days (TX90p) has increased globally with small exceptions in the southern part of South America (IPCC, 2021; Rusticucci et al., 2017). Over Europe an overall increase in the magnitude and frequency of high maximum temperatures has been observed over central Europe (Lorenz et al., 2019; Tomczyk and Bednorz, 2016; Twardosz and Kossowska-Cezak, 2013) and the southern-eastern part of Europe (Christidis et al., 2015; Croitoru et al., 2016a; Croitoru and Piticar, 2013; Fioravanti et al., 2016; Malinovic-Milicevic et al., 2016). To extended the overview also for the eastern part of Europe, in this study we provide an in-depth analysis of the trends and variability of hot and dry summers and 
their combined effect (e.g. compound events), in the eastern part of Europe and their large-scale drivers, extending the analysis period over more than 70 years (i.e. $1951-2020$ ).

The main conclusions of this study can be summarized as follows: i) the length, spatial extent and frequency of HWs in Romania has increased significantly over the last 70 years, for all summer months; ii) after the 1990's the rate of increase in the frequency, length and spatial extent has significantly accelerated; iii) the longest and most extensive (in term of spatial extent) HWs were observed in July 2012, August 2015 and June 2019; iv) no significant changes have been observed in the drought conditions at country level; v) there is no significant increase in the compound events (e.g. hot and dry summers) over the analyzed period and vi) the increased frequency of HWs especially after the 1990's could be partially explained by an increase in the geopotential height over the eastern part of Europe. in the north-western part and the Dobrogea region (Figure 4). Overall, an increase of the heat wave duration between 0.31 days/decade (in July) and 0.53 days/decade (in June) was observed (Table S1). The number of HWs started to increase in the 1990's reaching unprecedented length and spatial extent since 2000 until the end of the analyzed period (Figure 3). In terms of drought variability, no significant changes have been found. The monthly SPI shows an inhomogeneous pattern of change, with some regions experiencing drier condition (e.g. the north part of the country and Dobrogea region), while other regions have become wetter over the last 70 years (e.g. eastern, central and western part of the country) (Figure 7). This inhomogeneous pattern of change in the SPI is in agreement with previous studies which have shown that there is no spatial consistency in the occurrence of droughts, based on the SPI, over Romania (Cheval et al., 2014; Ionita et al., 2016) and also at European level (Ionita and Nagavciuc, 2021; Vicente-Serrano et al., 2021). The lack of homogeneity in the SPI variability, has led to a strong variability when looking at the combined analysis of both hot and dry summers. The most active decades, in terms of compound events, were $1951-1960,1991-2000$ and $2011-2020$. Throughout these periods, there were up to 4 combined hot and dry summers per decade, but their spatial distribution is different depending on the analyzed decade (Figure 9). Because the SPI has a very inhomogeneous spatial pattern, making it rather difficult to match the regions where also HWs occur, the identified number of CHDs over the analyzed period was relatively small at country level, and no clear trend has been observed in their frequency (not shown). Our results are not in agreement with other studies over different regions of Europe (De Luca et al., 2020; Russo et al., 2019; Vogel et al., 2021), regarding the frequency of compound events (e.g. hot and dry summers). All the aforementioned studies indicate that there is a significant increase in the frequency of CHD, especially over the Mediterranean region. This discrepancy might be due to the fact the over the Mediterranean region there is a homogenous trend regarding the drought conditions, thus hot and dry summers have a higher probability of occurring at the same time.

The occurrence of HWs in the eastern part of Europe was related to anticyclonic conditions and a higher frequency of blocking situations corroborated with daily maximum temperature anomalies up to $10^{\circ} \mathrm{C}$ (Figures S5 - S10). This is in agreement with previous study for other regions (e.g. western part of Europe) which have shown that HWs tend to occur under the influence of anticyclonic circulation, which is conductive to and intensification of the radiation flux and cloudless weather (Porebska and Zdunek, 2013; Tomczyk et al., 2017; Tomczyk and Bednorz, 2016). The occurrence of HWs over the analyzed region is 

variability as the HWDI index and the AREA index (Figure 2), thus supporting the finding that the increase in the number of HWs over the last 2 decades could be explained, at least partially, by the increase in the regional geopotential height. Similar results have been found also for the central and western part of Europe (Porebska and Zdunek, 2013; Tomczyk and Bednorz, 2016). In their study, Porebska and Zdunek (2013), have shown that heat waves over central part of Europe were often associated with an increased frequency of blocking situations over the Atlantic Ocean and Eastern Europe. Similar results have been found by Tomczyk and Bednorz (2016), which have shown that the occurrence of HWs in the central part of Europe, was mainly driven with positive anomalies of the Z500 over the analyzed region. Thus, a possible explanation regarding the increase in the frequency of HWs in Romania, over the past two decades, might be related to more frequent blocking situations and an increase in the geopotential height over the analyzed region (Figure 13). 


\section{References}

Bădăluță, C.-A., Perșoiu, A., Ionita, M., Nagavciuc, V., Bistricean, P.-I. P.-I., Persoiu, A., Ionita, M., Nagavciuc, V. and Bistricean, P.-I. P.-I.: Stable $\mathrm{H}$ and $\mathrm{O}$ isotope-based investigation of moisture sources and their role in river and groundwater recharge in the NE Carpathian Mountains, East-Central Europe, Isot. Environ. Heal. Stud., 55(2), 1-18, doi:https://doi.org/10.1080/10256016.2019.1588895, 2019.

Bakke, S. J., Ionita, M. and Tallaksen, L. M.: The 2018 northern European hydrological drought and its drivers in a historical perspective, Hydrol. Earth Syst. Sci., 24, 5621-5653, doi:10.5194/hess-2020-239, 2020.

Barriopedro, D., Fiscer, E. M., Luterbacher, J., Trigo, R. M. and García-Herrera, R.: The Hot Summer of 2010 : Map of Europe, Science (80-. )., 332(April), 220-224, doi:10.1080/10255842.2015.1069566, 2011.

Busuioc, A., Caian, M., Cheval, S., Bojariu, R., Boroneant, C., Baciu, M. and Dumitrescu, A.: Variabilitatea și schimbarea climei în România., 2010.

Busuioc, A., Dobrinescu, A., Birsan, M. V., Dumitrescu, A. and Orzan, A.: Spatial and temporal variability of climate extremes in Romania and associated large-scale mechanisms, Int. J. Climatol., 35(7), 1278-1300, doi:10.1002/joc.4054, 2015.

Chelcea, S., Ionita, M. and Adler, M.-J.: Identification of dry periods in the dobrogea region, IGI Global., 2015.

Chen, Y. and Li, Y.: An Inter-comparison of Three Heat Wave Types in China during 1961-2010: Observed Basic Features and Linear Trends, Sci. Rep., 7(April 2016), 2-11, doi:10.1038/srep45619, 2017.

Cheval, S., Busuioc, A., Dumitrescu, A. and Birsan, M. V.: Spatiotemporal variability of meteorological drought in Romania using the standardized precipitation index (SPI), Clim. Res., 60(3), 235-248, doi:10.3354/cr01245, 2014.

Christidis, N., Jones, G. S. and Stott, P. A.: Dramatically increasing chance of extremely hot summers since the 2003 European heatwave, Nat. Clim. Chang., 5(1), 46-50, doi:10.1038/nclimate2468, 2015.

Cornes, R. C., Schrier, G. Van Der, Besselaar, E. J. M. Van Den and Jones, P. D.: An Ensemble Version of the E-OBS Temperature and Precipitation Datasets, Geophys. Res. Atom, 123, doi:10.1029/2017JD028200, 2018.

Croitoru, A.-E., Piticar, A., Ciupertea, A.-F. and Roşca, C. F.: Changes in heat waves indices in Romania over the period 1961-2015, Glob. Planet. Change, 146, 109-121, doi:https://doi.org/10.1016/j.gloplacha.2016.08.016, $2016 \mathrm{a}$.

Croitoru, A. E. and Piticar, A.: Changes in daily extreme temperatures in the extra-Carpathians regions of Romania, Int. J. Climatol., 33(8), 1987-2001, doi:10.1002/joc.3567, 2013.

Croitoru, A. E., Piticar, A., Ciupertea, A. F. and Roşca, C. F.: Changes in heat waves indices in Romania over the period 1961-2015, Glob. Planet. Change, 146, 109-121, doi:10.1016/j.gloplacha.2016.08.016, 2016b.

Della-Marta, P. M., Luterbacher, J., von Weissenfluh, H., Xoplaki, E., Brunet, M. and Wanner, H.: Summer heat waves over western Europe 1880-2003, their relationship to large-scale forcings and predictability, Clim. Dyn., doi:10.1007/s00382-007-0233-1, 2007.

Dima, V., Georgescu, F., Irimescu, A. and Mihailescu, D.: Valuri de caldura in Romania, Editura PRINTECH., 2016.

Dumitrescu, A. and Birsan, M.: ROCADA: a gridded daily climatic dataset over Romania (1961 - 2013) for nine meteorological variables, Nat. Hazards, 78, 1045-1063, doi:10.1007/s11069-015-1757-z, 2015.

Feng, S., Wu, X., Hao, Z., Hao, Y., Zhang, X. and Hao, F.: A database for characteristics and variations of global compound dry and hot events, Weather Clim. Extrem., 30, 100299, doi:https://doi.org/10.1016/j.wace.2020.100299, 2020.

Fioravanti, G., Piervitali, E. and Desiato, F.: Recent changes of temperature extremes over Italy: an index-based analysis, 
Theor. Appl. Climatol., 123(3), 473-486, doi:10.1007/s00704-014-1362-1, 2016.

Gao, T., Yu, J. and Paek, H.: Impacts of four northern-hemisphere teleconnection patterns on atmospheric circulations over Eurasia and the Pacific, Theor. Appl. Climatol., 129(3), 815-831, doi:10.1007/s00704-016-1801-2, 2017.

Geirinhas, J. L., Russo, A., Libonati, R., Sousa, P. M., Miralles, D. G. and Trigo, R. M.: Recent increasing frequency of compound summer drought and heatwaves in Southeast Brazil, Environ. Res. Lett., 16(3), 034036, doi:10.1088/17489326/abe0eb, 2021.

Gocheva, A., Trifonova, L., Marinova, T. and Bocheva, L.: Extreme Hot Spells and Heat Waves on the Territory of Bulgaria, ResearchGate [online] Available from:

https://www.researchgate.net/publication/240615319_Extreme_Hot_Spells_and_Heat_Waves_on_the_Territory_of_Bulgari a, 2006.

Grams, C. M., Binder, H., Pfahl, S., Piaget, N. and Wernli, H.: Atmospheric processes triggering the central European floods in June 2013, Nat. Hazards Earth Syst. Sci., 14(7), 1691-1702, doi:10.5194/nhess-14-1691-2014, 2014.

Hersbach, H., Bell, B., Berrisford, P., Hirahara, S., Horányi, A., Muñoz-Sabater, J., Nicolas, J., Peubey, C., Radu, R., Schepers, D., Simmons, A., Soci, C., Abdalla, S., Abellan, X., Balsamo, G., Bechtold, P., Biavati, G., Bidlot, J., Bonavita, M., De Chiara, G., Dahlgren, P., Dee, D., Diamantakis, M., Dragani, R., Flemming, J., Forbes, R., Fuentes, M., Geer, A., Haimberger, L., Healy, S., Hogan, R. J., Hólm, E., Janisková, M., Keeley, S., Laloyaux, P., Lopez, P., Lupu, C., Radnoti, G., de Rosnay, P., Rozum, I., Vamborg, F., Villaume, S. and Thépaut, J.-N.: The ERA5 global reanalysis, Q. J. R. Meteorol. Soc., 146(730), 1999-2049, doi:https://doi.org/10.1002/qj.3803, 2020.

Horton, D. E., Johnson, N. C., Singh, D., Swain, D. L., Rajaratnam, B. and Diffenbaugh, N. S.: Contribution of changes in atmospheric circulation patterns to extreme temperature trends, Nature, 522(7557), 465-469, doi:10.1038/nature14550, 2015.

Hustiu, M. C.: Cold and heat waves in the Barlad Plateau between 1961 and 2013, Riscuri si Catastr., 18, 31-42, 2016.

Ionita, M. and Nagavciuc, V.: Changes in drought features at the European level over the last 120 years., 2021.

Ionita, M., Lohmann, G., Rimbu, N., Chelcea, S. and Dima, M.: Interannual to decadal summer drought variability over Europe and its relationship to global sea surface temperature, Clim. Dyn., 38(1-2), 363-377, doi:10.1007/s00382-011-1028y, 2012.

Ionita, M., Dima, M., Lohmann, G., Scholz, P. and Rimbu, N.: Predicting the June 2013 European Flooding Based on Precipitation, Soil Moisture, and Sea Level Pressure, J. Hydrometeorol., 16(2), 598-614, doi:10.1175/JHM-D-14-0156.1, 2015a.

Ionita, M., Scholz, P. and Chelcea, S.: Spatio-temporal variability of dryness/wetness in the Danube River Basin, Hydrol. Process., 29(20), 4483-4497, doi:10.1002/hyp.10514, 2015 b.

Ionita, M., Scholz, P. and Chelcea, S.: Assessment of droughts in Romania using the Standardized Precipitation Index, Nat. Hazards, 81(3), 1483-1498, doi:10.1007/s11069-015-2141-8, 2016.

Ionita, M., Tallaksen, L. M., Kingston, D. G., Stagge, J. H., Laaha, G., Van Lanen, H. A. J., Scholz, P., Chelcea, S. M., Haslinger, K., Lanen, H. A. J. Van, Chelcea, S. M., Haslinger, K., Scholz, P., Chelcea, S. M. and Haslinger, K.: The European 2015 drought from a climatological perspective, Hydrol. Earth Syst. Sci., 21, 1397-1419, doi:doi:10.5194/hess21-1397-2017, 2017.

Ionita, M., Nagavciuc, V., Kumar, R. and Rakovec, O.: On the curious case of the recent decade, mid-spring precipitation deficit in central Europe, npj Clim. Atmos. Sci., 3(1), 49, doi:10.1038/s41612-020-00153-8, 2020.

Ionita, M., Caldarescu, D. E. and Nagavciuc, V.: Compound Hot and Dry Events in Europe: Variability and Large-Scale Drivers, Front. Clim., 3, 58, doi:10.3389/fclim.2021.688991, 2021a. 
Ionita, M., Dima, M., Nagavciuc, V., Scholz, P. and Lohmann, G.: Past megadroughts in central Europe were longer, more severe and less warm than modern droughts, Commun. Earth Environ., 2(1), 61, doi:10.1038/s43247-021-00130-w, 2021 b.

IPCC: Climate Change 2021: The Physical Science Basis. Contribution of Working Group I to the Sixth Assessment Report of the Intergovernmental Panel on Climate Change, edited by V. Masson-Delmotte, P. Zhai, A. Pirani, S. L. Connors, C. Péan, S. Berger, N. Caud, Y. Chen, L. Goldfarb, M. I. Gomis, M. Huang, K. Leitzell, E. Lonnoy, J. B. R. Matthews, T. K. Maycock, T. Waterfield, O. Yelekçi, R. Yu, and B. Zhou, Cambridge University Press. In Press., 2021.

Jeong, D. Il, Yu, B. and Cannon, A. J.: Links between atmospheric blocking and North American winter cold spells in two generations of Canadian Earth System Model large ensembles, Clim. Dyn., 57(7), 2217-2231, doi:10.1007/s00382-021-

578 05801-0, 2021

Kautz, L.-A., Martius, O., Pfahl, S., Pinto, J. G., Ramos, A. M., Sousa, P. M. and Woollings, T.: Atmospheric Blocking and Weather Extremes over the Euro-Atlantic Sector -- A Review, Weather Clim. Dyn. Discuss., 2021, 1-43, doi:10.5194/wcd2021-56, 2021.

Kingston, D. G., Lawler, D. M. and McGregor, G. R.: Linkages between atmospheric circulation, climate and streamflow in 2006 .

Kingston, D. G., Stagge, J. H., Tallaksen, L. M. and Hannah, D. M.: European-Scale Drought : Understanding Connections between Atmospheric Circulation and Meteorological Drought Indices, J. Clim., 28(2), 505-516, doi:10.1175/JCLI-D-14$00001.1,2015$.

Kong, Q., Guerreiro, S. B., Blenkinsop, S., Li, X.-F. and Fowler, H. J.: Increases in summertime concurrent drought and heatwave in Eastern China, Weather Clim. Extrem., 28, 100242, doi:https://doi.org/10.1016/j.wace.2019.100242, 2020.

Laaha, G., Gauster, T., Tallaksen, L. M. L. M., Vidal, J.-P. J. P., Stahl, K., Prudhomme, C., Heudorfer, B., Vlnas, R., Ionita, M., Van Lanen, H. A. J. H. A. J., Adler, M. J. M.-J., Caillouet, L., Delus, C., Fendekova, M., Gailliez, S., Hannaford, J., Kingston, D., Van Loon, A. F. A. F., Mediero, L., Osuch, M., Romanowicz, R. J., Sauquet, E., Stagge, J. H. J. H., Wong, W. K. W. K., Scholz, P., Van Lanen, H. A. J. H. A. J., Adler, M. J. M.-J., Caillouet, L., Delus, C., Fendekova, M., Gailliez, S., Hannaford, J., Kingston, D., Van Loon, A. F. A. F., Mediero, L., Osuch, M., Romanowicz, R. J., Sauquet, E., Stagge, J. H. J. H. and Wong, W. K. W. K.: The European 2015 drought from a hydrological perspective, Hydrol. Earth Syst. Sci., 21(3), 3001-3024, doi:10.5194/hess-21-3001-2017, 2017.

Van Lanen, H. A. J. H. A. J., Laaha, G., Kingston, D. G. D. G., Gauster, T., Ionita, M., Vidal, J.-P. J. P., Vlnas, R., Romanowicz, R. J. R. J., Gailliez, S., Wong, W. K. W. K., Adler, M. J. M.-J., Blauhut, V., Caillouet, L., Chelcea, S., Frolova, N., Gudmundsson, L., Hanel, M., Haslinger, K., Kireeva, M., Osuch, M., Sauquet, E., Stagge, J. H. J. H. and Van

601 Loon, A. F. A. F.: Hydrology needed to manage droughts: the 2015 European case, Hydrol. Process., 30(17), 3097-3104, 602 doi:10.1002/hyp.10838, 2016.

Leonard, M., Westra, S., Phatak, A., Lambert, M., van den Hurk, B., McInnes, K., Risbey, J., Schuster, S., Jakob, D. and Stafford-Smith, M.: A compound event framework for understanding extreme impacts, WIREs Clim. Chang., 5(1), 113128, doi:https://doi.org/10.1002/wcc.252, 2014. 
613 McKee, T. B., Nolan, J. and Kleist, J.: The relationship of drought frequency and duration yo time scales, Eighth Conf.

614 Appl. Climatol. 17-22 January 1993, Anaheim, Calif., 1-6, doi:10.1002/jso.23002, 1993.

615 Micu, D. M., Amihaesei, V. A., Milian, N. and Cheval, S.: Recent changes in temperature and precipitation indices in the

616 Southern Carpathians, Romania (1961-2018), Theor. Appl. Climatol., 144(1), 691-710, doi:10.1007/s00704-021-03560-w,

6172021.

618 Nagavciuc, V., Ionita, M., Perșoiu, A., Popa, I., Loader, N. J. and McCarroll, D.: Stable oxygen isotopes in Romanian oak

619 tree rings record summer droughts and associated large-scale circulation patterns over Europe, Clim. Dyn., 52(11),

620 doi:10.1007/s00382-018-4530-7, 2019.

621 Najibi, N., Devineni, N., Lu, M. and Perdigão, R. A. P.: Coupled flow accumulation and atmospheric blocking govern flood 622 duration, npj Clim. Atmos. Sci., 2(1), 19, doi:10.1038/s41612-019-0076-6, 2019.

623 Perkins, S. E. and Alexander, L. V: On the Measurement of Heat Waves, J. Clim., 26(13), 4500-4517, doi:10.1175/JCLI-D$624 \quad 12-00383.1,2013$.

625 Porebska, M. and Zdunek, M.: Analysis of extreme temperature events in Central Europe related to high pressure blocking

626 situations in 2001?2011, Meteorol. Zeitschrift, 22(5), 533-540, doi:10.1127/0941-2948/2013/0455, 2013.

627 Prăvălie, R., Bandoc, G., Patriche, C. and Tomescu, M.: Spatio-temporal trends of mean air temperature during 1961-2009

628 and impacts on crop (maize) yields in the most important agricultural region of Romania, Stoch. Environ. Res. Risk Assess.,

629 31(8), 1923-1939, doi:10.1007/s00477-016-1278-7, 2017.

630 Raymond, C., Horton, R. M., Zscheischler, J., Martius, O., AghaKouchak, A., Balch, J., Bowen, S. G., Camargo, S. J., Hess, 631 J., Kornhuber, K., Oppenheimer, M., Ruane, A. C., Wahl, T. and White, K.: Understanding and managing connected 632 extreme events, Nat. Clim. Chang., 10(7), 611-621, doi:10.1038/s41558-020-0790-4, 2020.

633 Rey, G., Jougla, E., Fouillet, A., Pavillon, G., Bessemoulin, P., Frayssinet, P., Clavel, J. and Hémon, D.: The impact of 634 major heat waves on all-cause and cause-specific mortality in France from 1971 to 2003, Int. Arch. Occup. Environ. Health, 635 80(7), 615-626, doi:10.1007/s00420-007-0173-4, 2007.

Ridder, N. N., Pitman, A. J., Westra, S., Ukkola, A., Do, H. X., Bador, M., Hirsch, A. L., Evans, J. P., Di Luca, A. and 637 Zscheischler, J.: Global hotspots for the occurrence of compound events, Nat. Commun., 11(1), 5956, doi:10.1038/s41467638 020-19639-3, 2020.

639 Rimbu, N., Dima, M., Lohmann, G. and Stefan, S.: Impacts of the North Atlantic Oscillation and the El Niño-Southern 640 Oscillation on Danube river flow variability, Geophys. Res. Lett., 31(23), 1-4, doi:10.1029/2004GL020559, 2004.

641 Rimbu, N., Lohmann, G. and Ionita, M.: Interannual to multidecadal Euro-Atlantic blocking variability during winter and its 642 relationship with extreme low temperatures in Europe, J. Geophys. Res. Atmos., 119(24), 13621-13636,

643 doi:10.1002/2014JD021983, 2014.

644 Robinson, P. J.: On the Definition of a Heat Wave, J. Appl. Meteorol., 40(4), 762-775, doi:10.1175/1520-

645 0450(2001)040<0762:OTDOAH>2.0.CO;2, 2001.

646 Russo, A., Gouveia, C. M., Dutra, E., Soares, P. M. M. and Trigo, R. M.: The synergy between drought and extremely hot 647 summers in the Mediterranean, Environ. Res. Lett., 14(1), 014011, doi:10.1088/1748-9326/aaf09e, 2019.

648 Rusticucci, M., Barrucand, M. and Collazo, S.: Temperature extremes in the Argentina central region and their monthly 649 relationship with the mean circulation and ENSO phases, Int. J. Climatol., 37(6), 3003-3017,

650 doi:https://doi.org/10.1002/joc.4895, 2017. 

precipitation deficits, J. Clim., doi:10.1175/JCLI-D-15-0452.1, 2016.

Seneviratne, S. I., Nicholls, N., Easterling, D., Goodess, C. M., Kanae, S., Kossin, J., Luo, Y., Marengo, J., McInnes, K.,

Rahimi, M., Reichstein, M., Sorteberg, A., Vera, C., Zhang, X., Rusticucci, M., Semenov, V., Alexander, L. V, Allen, S., Benito, G., Cavazos, T., Clague, J., Conway, D., Della-Marta, P. M., Gerber, M., Gong, S., Goswami, B. N., Hemer, M., Huggel, C., van den Hurk, B., Kharin, V. V, Kitoh, A., Tank, A. M. G. K., Li, G., Mason, S., McGuire, W., van Oldenborgh, G. J., Orlowsky, B., Smith, S., Thiaw, W., Velegrakis, A., Yiou, P., Zhang, T., Zhou, T. and Zwiers, F. W.: Changes in Climate Extremes and their Impacts on the Natural Physical Environment, in Managing the Risks of Extreme Events and Disasters to Advance Climate Change Adaptation: Special Report of the Intergovernmental Panel on Climate Change, edited by C. B. Field, Q. Dahe, T. F. Stocker, and V. Barros, pp. 109-230, Cambridge University Press, Cambridge., 2012.

Sfîcă, L., Croitoru, A.-E., Iordache, I. and Ciupertea, A.-F.: Synoptic Conditions Generating Heat Waves and Warm Spells in Romania, Atmosphere (Basel)., 8(3), doi:10.3390/atmos8030050, 2017.

Shevchenko, O., Lee, H., Snizhko, S. and Mayer, H.: Long-term analysis of heat waves in Ukraine, Int. J. Climatol., 34(5), 1642-1650, doi:https://doi.org/10.1002/joc.3792, 2014.

670

Sidău, M. R., Croitoru, A.-E. and Alexandru, D.-E.: Comparative Analysis between Daily Extreme Temperature and Precipitation Values Derived from Observations and Gridded Datasets in North-Western Romania, Atmosphere (Basel)., 12(3), doi:10.3390/atmos12030361, 2021.

Smoyer-Tomic, K. E., Kuhn, R. and Hudson, A.: Heat Wave Hazards: An Overview of Heat Wave Impacts in Canada, Nat. Hazards, 28(2), 465-486, doi:10.1023/A:1022946528157, 2003.

Spinoni, J., Naumann, G., Vogt, J. V. and Barbosa, P.: The biggest drought events in Europe from 1950 to 2012, J. Hydrol. Reg. Stud., 3, 509-524, doi:10.1016/j.ejrh.2015.01.001, 2015.

Swain, D. L., Horton, D. E., Singh, D. and Diffenbaugh, N. S.: Trends in atmospheric patterns conducive to seasonal precipitation and temperature extremes in California, Sci. Adv., 2(4), 1-14, doi:10.1126/sciadv.1501344, 2016.

Tomczyk, A. M. and Bednorz, E.: Heat waves in Central Europe and their circulation conditions, Int. J. Climatol., 36(2), 770-782, doi:https://doi.org/10.1002/joc.4381, 2016.

Tomczyk, A. M., Półrolniczak, M. and Bednorz, E.: Circulation Conditions' Effect on the Occurrence of Heat Waves in Western and Southwestern Europe, Atmosphere (Basel)., 8(2), doi:10.3390/atmos8020031, 2017.

Tomozeiu, R., Stefan, S. and Busuioc, A.: Winter precipitation variability and large-scale circulation patterns in Romania, Theor. Appl. Clim., 81, 193-201, doi:10.1007/s00704-004-0082-3, 2005.

Twardosz, R. and Kossowska-Cezak, U.: Exceptionally hot summers in Central and Eastern Europe (1951-2010), Theor. Appl. Climatol., 112(3-4), 617-628, doi:10.1007/s00704-012-0757-0, 2013.

Vaideanu, P., Dima, M., Pirloaga, R. and Ionita, M.: Disentangling and quantifying contributions of distinct forcing factors to the observed global sea level pressure field, Clim. Dyn., 54(3-4), doi:10.1007/s00382-019-05067-7, 2020.

Vicente-Serrano, S. M. and López-Moreno, J. I.: Nonstationary influence of the North Atlantic Oscillation on European precipitation, J. Geophys. Res. Atmos., 113(20), 1-14, doi:10.1029/2008JD010382, 2008.

Vicente-Serrano, S. M., Domínguez-Castro, F., Murphy, C., Hannaford, J., Reig, F., Peña-Angulo, D., Tramblay, Y., Trigo, R. M., Mac Donald, N., Luna, M. Y., Mc Carthy, M., der Schrier, G., Turco, M., Camuffo, D., Noguera, I., García-Herrera, R., Becherini, F., Della Valle, A., Tomas-Burguera, M. and El Kenawy, A.: Long-term variability and trends in meteorological droughts in Western Europe (1851-2018), Int. J. Climatol., 41(S1), E690-E717, 
https://doi.org/10.5194/nhess-2021-298

Preprint. Discussion started: 2 November 2021

(c) Author(s) 2021. CC BY 4.0 License.

695 doi:https://doi.org/10.1002/joc.6719, 2021.

696 Vogel, J., Paton, E., Aich, V. and Bronstert, A.: Increasing compound warm spells and droughts in the Mediterranean Basin,

697 Weather Clim. Extrem., 32, 100312, doi:https://doi.org/10.1016/j.wace.2021.100312, 2021.

698 Zscheischler, J. and Seneviratne, S. I.: Dependence of drivers affects risks associated with compound events, Sci. Adv.,

699 3(6), 1-11, doi:10.1126/sciadv.1700263, 2017.

700 Zscheischler, J., Westra, S., Van Den Hurk, B. J. J. M., Seneviratne, S. I., Ward, P. J., Pitman, A., Aghakouchak, A.,

701

Bresch, D. N., Leonard, M., Wahl, T. and Zhang, X.: Future climate risk from compound events, Nat. Clim. Chang., 8(6),

702 469-477, doi:10.1038/s41558-018-0156-3, 2018.

703

704

705

706

707

708

709

710

711

712

713

714

715

716

717

718

719

720

721

722

723

724 
Author Contributions. VN and MI designed the study, wrote the paper and interpret the results. All authors (i.e. VN, PS and MI) contributed equally to the article.

Acknowledgments. Viorica Nagavciuc was supported by a grant of the Ministry of Research, Innovation and Digitization, CNCS/CCCDI - UEFISCDI, project number PN-III-P1-1.1-PD-2019-0469, within PNCDI III. Monica Ionita and Patrick Scholz are supported by Helmholtz Association through the joint program "Changing Earth - Sustaining our Future" (PoF IV) program of the AWI. Funding by the Helmholtz Climate Initiative REKLIM, the AWI Strategy Fund Project - PalEX and the project S2: Improved parameterisations and numerics in climate models, of the collaborative Research Center TRR181 "Energy Trasnfer in the Atmosphere and Ocean" (DFG) - Projektnummer 274762653 are gratefully acknowledged.

Data availability. The data that support the findings of this study are available from the corresponding author upon reasonable request.

Financial support. The article processing charges for this open access publication were covered by the Alfred Wegener Institute, Helmholtz Centre for Polar and Marine Research (AWI). 
https://doi.org/10.5194/nhess-2021-298

Preprint. Discussion started: 2 November 2021

(c) Author(s) 2021. CC BY 4.0 License.

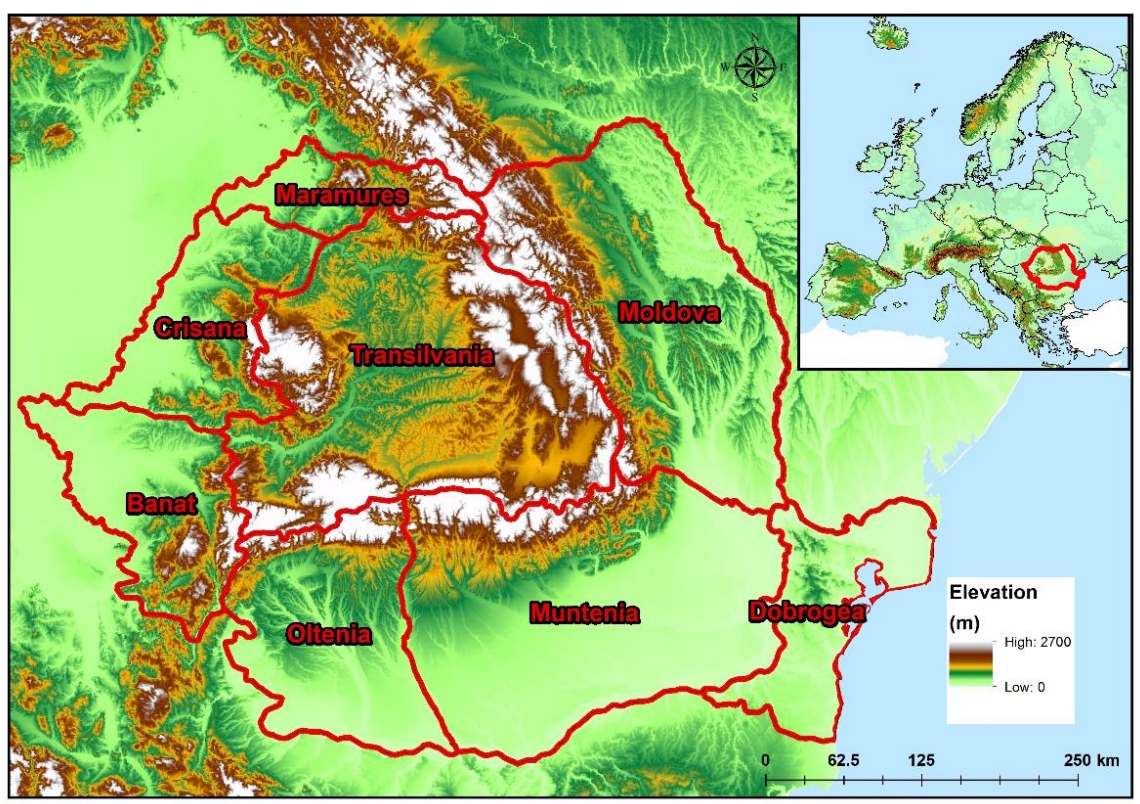

Figure 1. The topographic map of Romania and the location of the country at European level 

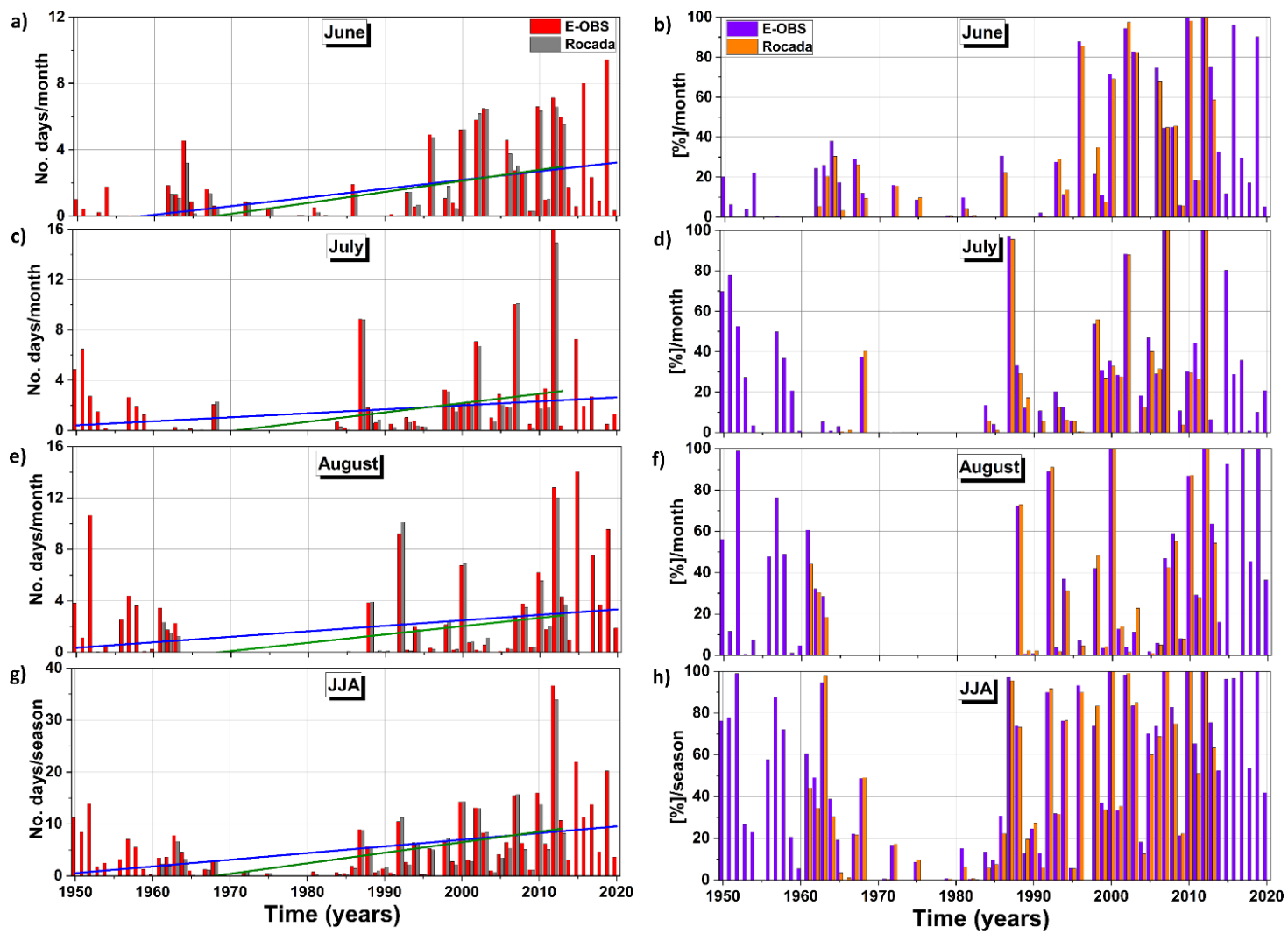

Figure 2. Monthly and seasonal temporal evolution of the summer heat waves duration (HWDI) averaged at country level (left column) and the temporal evolution of the percentage area (AREA) affected by heat waves (right column) over period 1950 - 2020: a) June HWDI; b) June AREA; c) July HWDI; d) July AREA; e) August HWDI; f) August AREA; g) Summer (JJA) HWDI and h) Summer (JJA) AREA. The orange lines indicate the time series obtained based on the EOBA data set and the blue lines indicted the time series obtained based on the ROCADA dataset. The blue line indicates the linear trend line based on the E-OBS data and the green line represent the linear trend line based on the ROCDA data. 


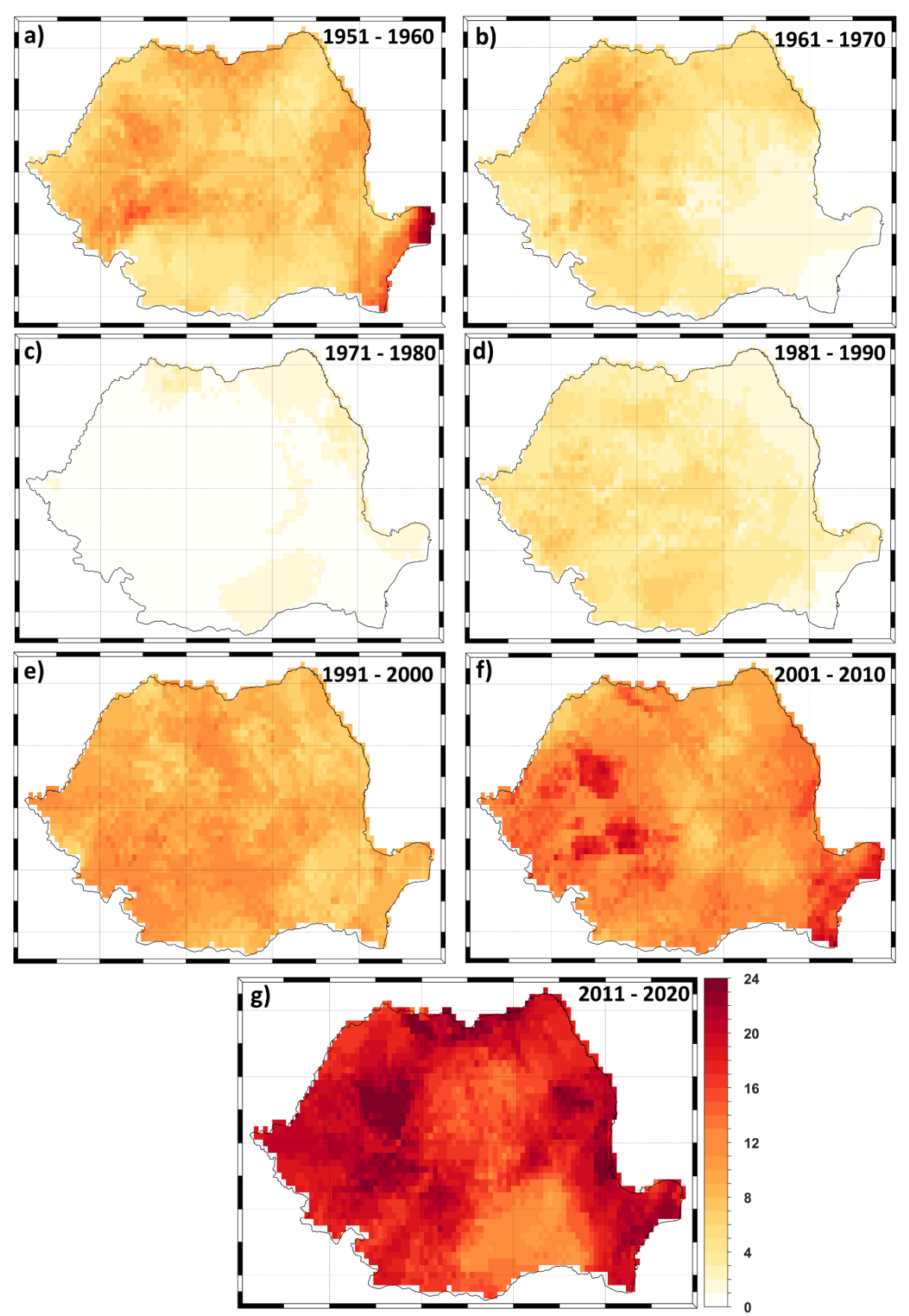

Figure 3. Decadal frequency of the number of summer heat waves (HWs) per decade over the last 70 years: a) 1951 - 1960; b) $1961-1970$; c) $1971-1980$; d) $1981-1990$; e) $1991-2000$; f) $2001-2010$ and g) $2011-2020$. Units: number of HWs/decade. 

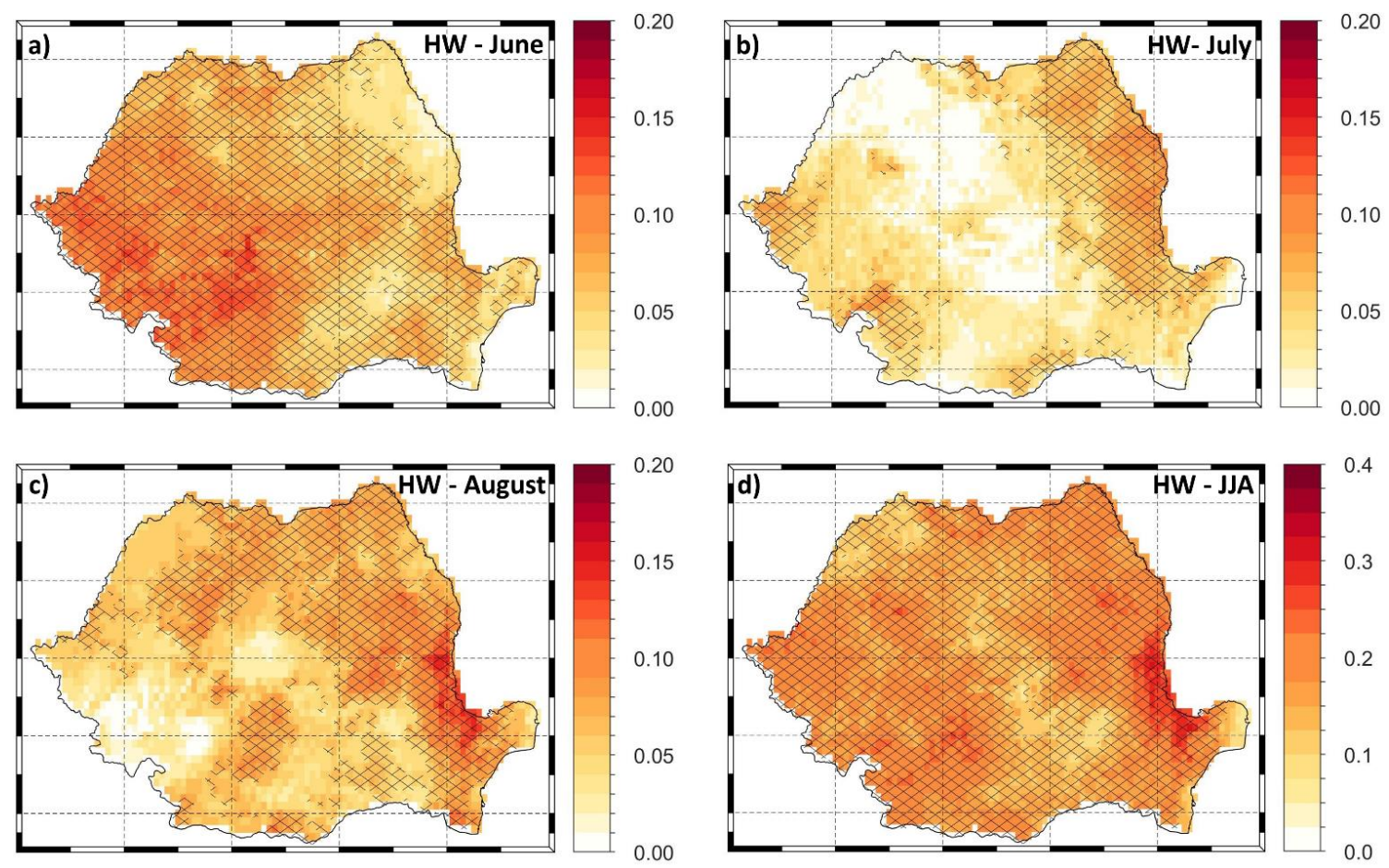

Figure 4. Linear trend of the numer heat waves for: a) june; b) July; c) August and d) JJA. Stipples indicate statistically significant trends. Units: number of HWs/decade. Analyzed period $1950-2020$. 
a)

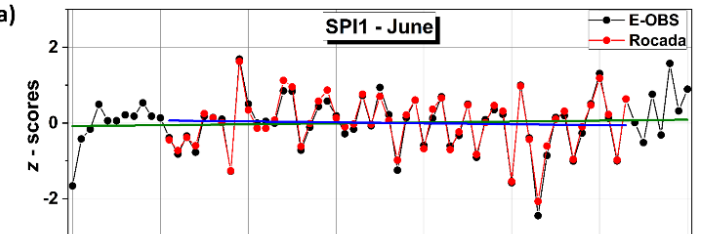

c)

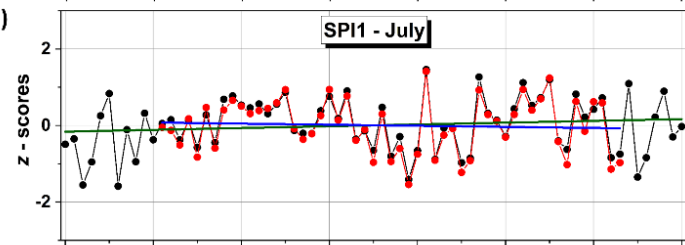

e)

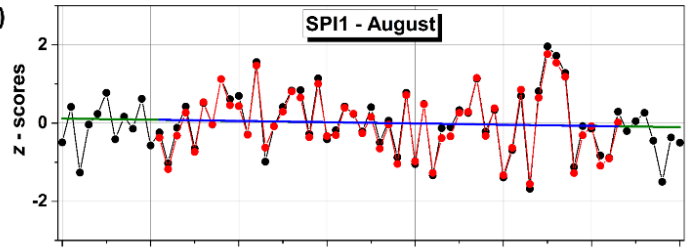

g)

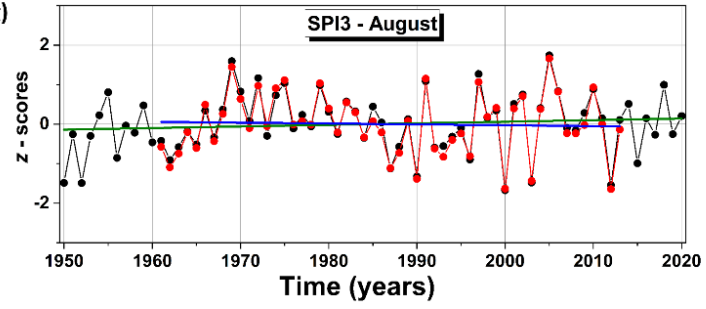

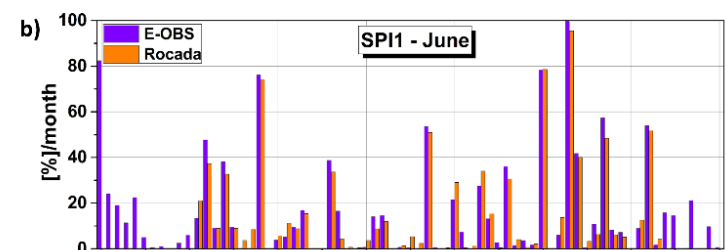

d)

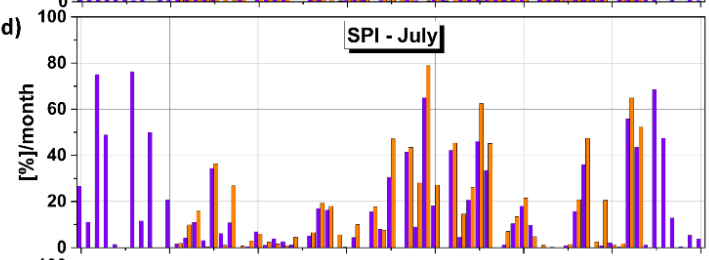

f)

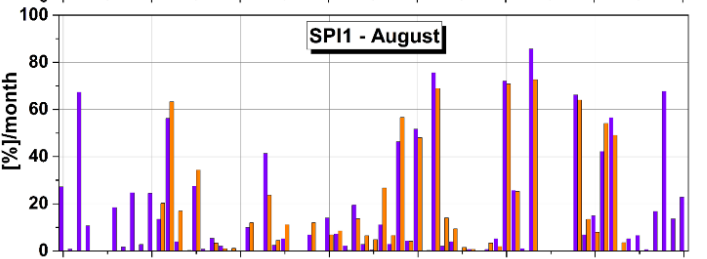

h)

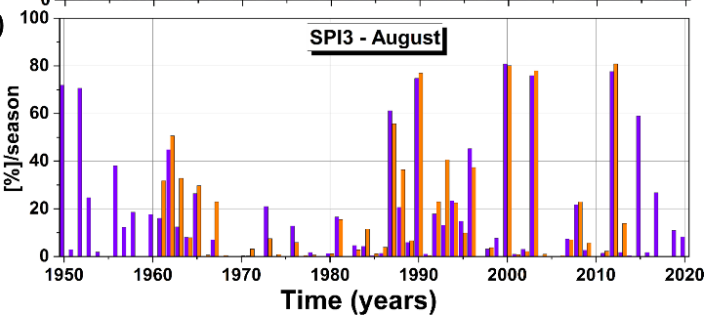

Figure 5. Monthly and seasonal temporal evolution of the SPI index averaged at country level (left column) and the temporal evolution of the percentage area (AREA) affected by drought conditions (SPI < -1) right column) over period 1950 - 2020: a) June SPI1; b) June drought AREA; c) July SPI1 ; d) July drought AREA; e) August SPI1; f) August drought AREA; g) August SPI3 (indicator of dry/wet condition over the summer seasons) and h) August SPI3 drought AREA. The orange lines indicate the time series obtained based on the E-OBA data set and the blue lines indicted the time series obtained based on the ROCADA dataset. The blue line indicates the linear trend line based on the E-OBS data and the green line represent the linear trend line based on the ROCDA data. 


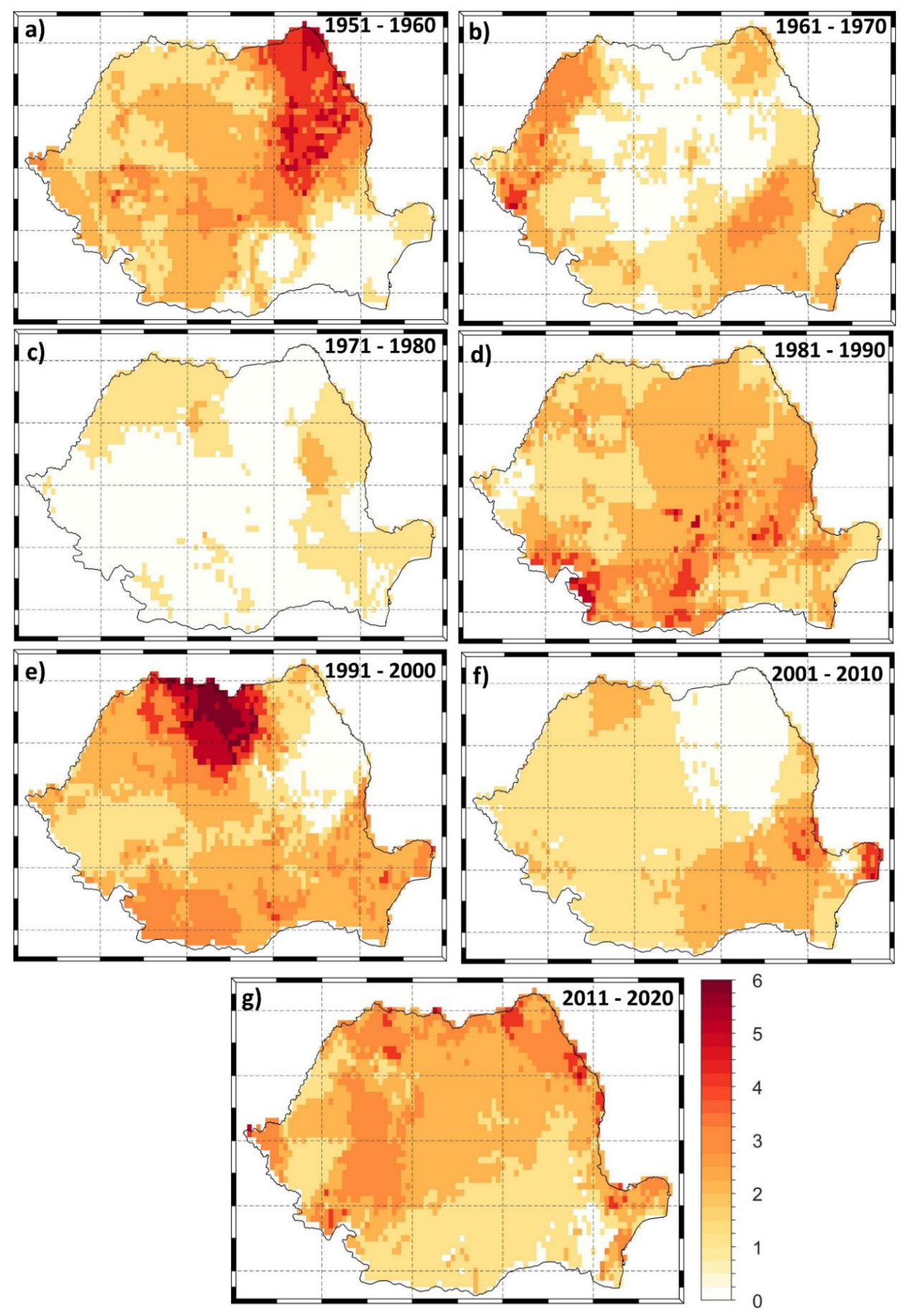

Figure 6. Decadal frequency of August SPI 3 over the last 70 years for the cases when August SPI3 <-1: a) 1951 - 1960; b) $1961-1970$; c) $1971-1980$; d) 1981 - 1990; e) 1991 - 2000; f) $2001-2010$ and g) $2011-2020$. Units: number of dry summers/decade. 
https://doi.org/10.5194/nhess-2021-298

Preprint. Discussion started: 2 November 2021

(c) Author(s) 2021. CC BY 4.0 License.

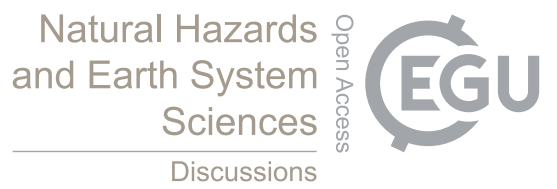

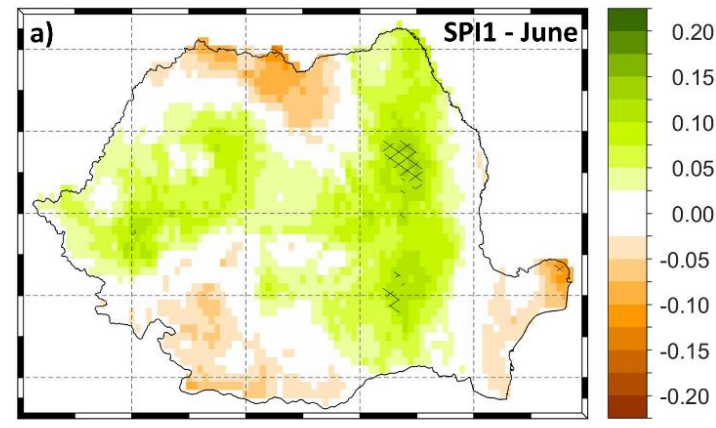

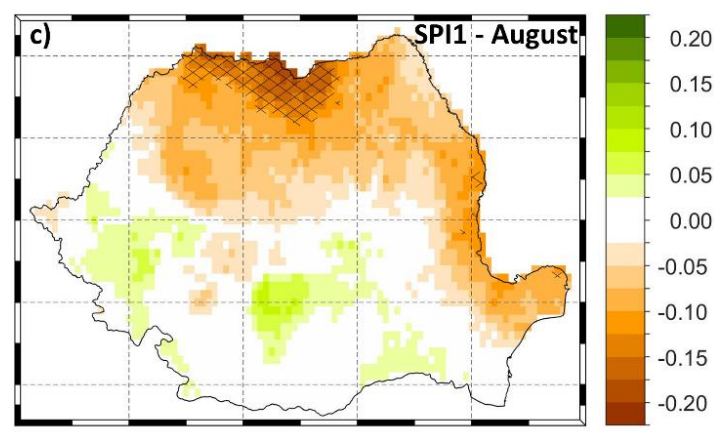

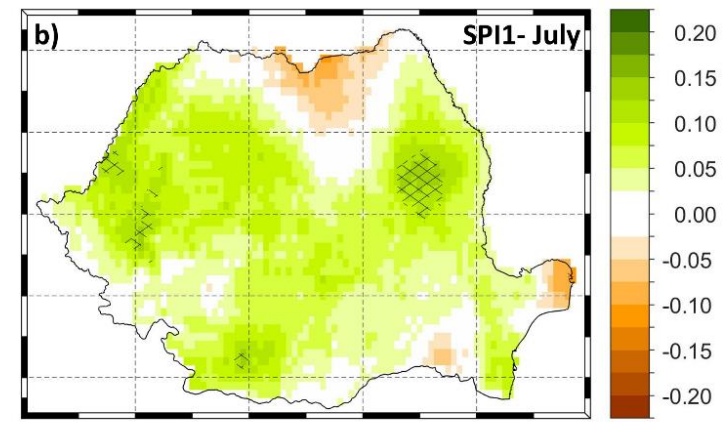

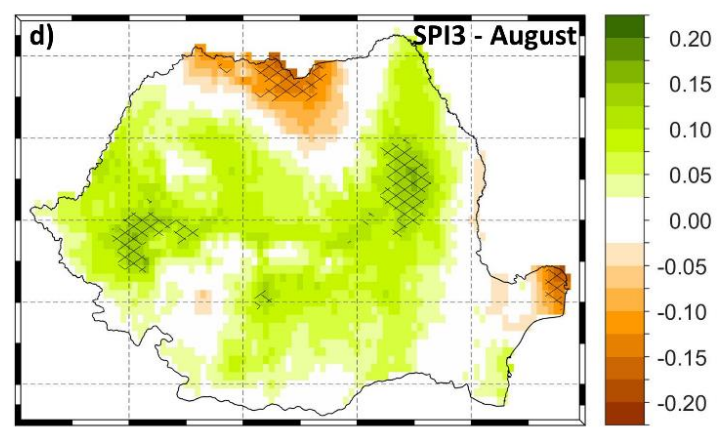

Figure 7. Linear trend of: a) June SPI1; b) July SPI1; c) August SPI1 and d) the Augsut SPI3. Stipples indicate statistically significant trends. Units: number of z-scores/decade. Analyzed period $1950-2020$. 

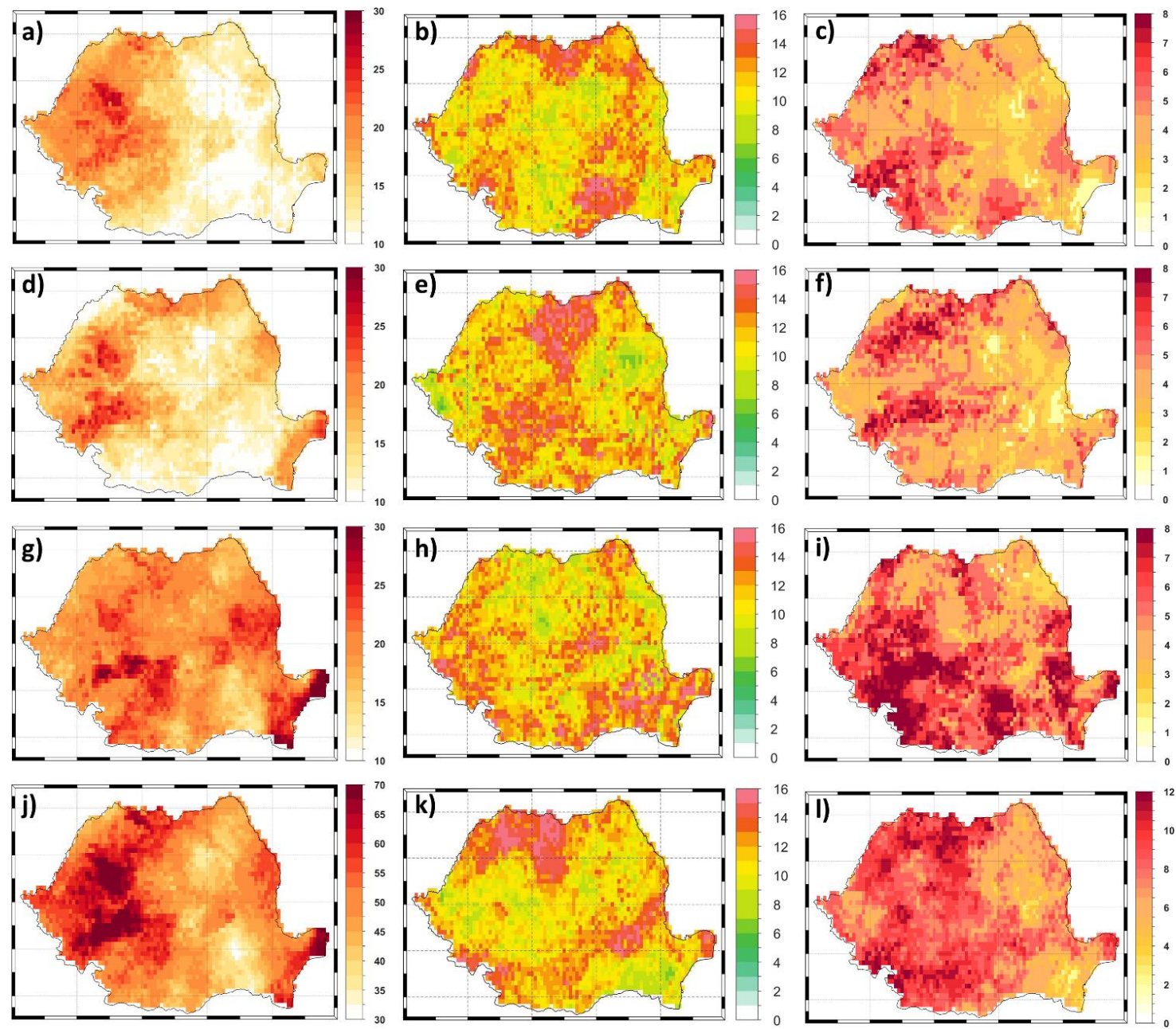

Figure 8. Frequency of monthly and seasonal HWs (first column), drought conditions (SPI<-1, second column) and compound hot and dry (CHD, third column over the whole analyzed period 1950 - 2020. a) June HWs; b) June SPI1; c) June CHD; d) July HWs; e) July SPI1; f) July CHD; g) August HWs; h) August SPI1; i) August CHD; j) Summer (JJA) HWs, k) August SPI3 and i) Summer (JJA) CHD. Units: HW (number of HWs/ 71 years), SPI (number of dry months/ 71 years) and CHD (number of CHDs/ 71 years). 


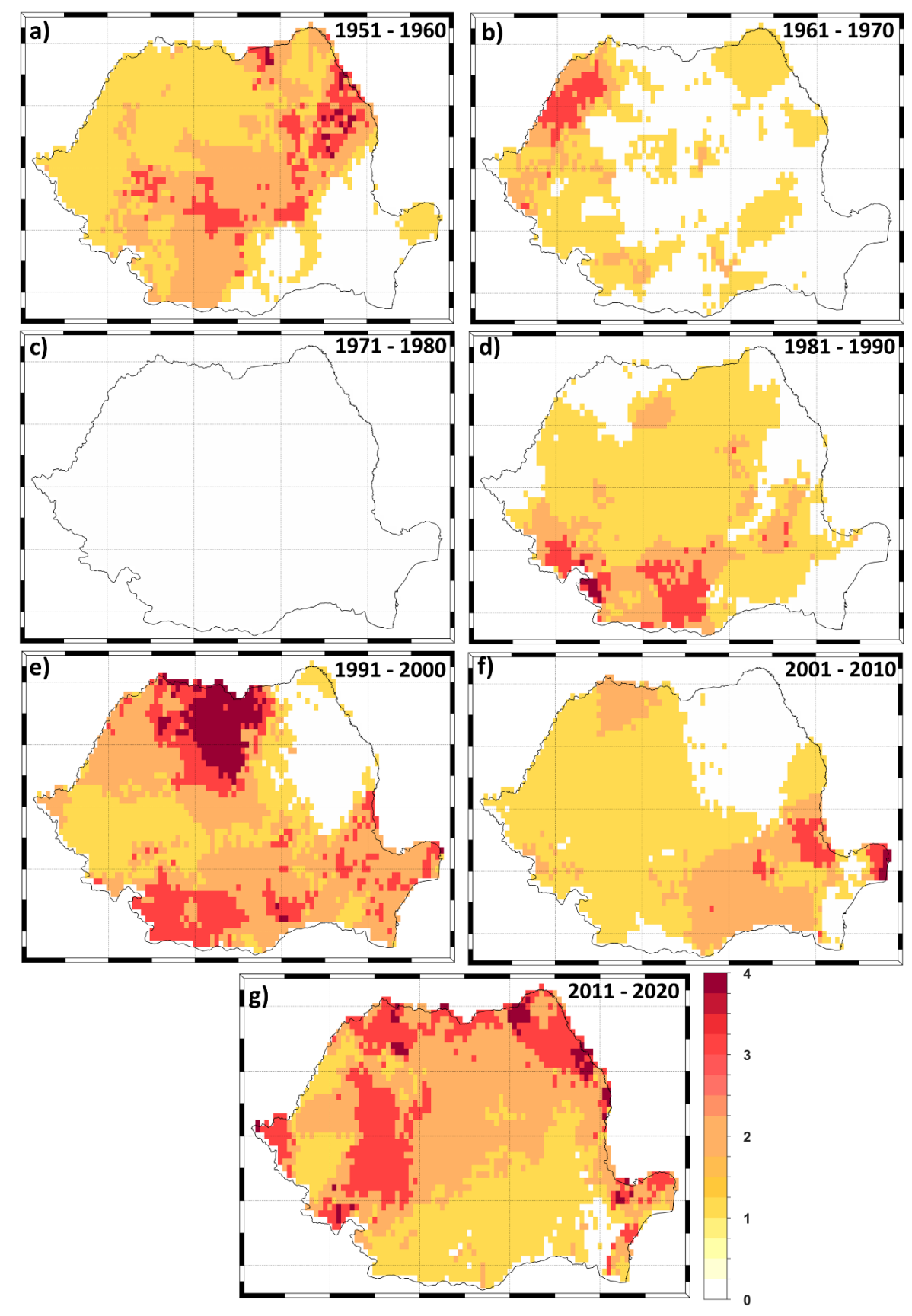

Figure 9. Decadal frequency of the number of compound hot and dry summer (CHDs) per decade over the last 70 years: a) 1951 - 1960; b) 1961 - 1970; c) 1971 - 1980; d) 1981 - 1990;

e) $1991-2000$; f) $2001-2010$ and g) 2011 - 2020. Units: number of CHDs/decade. 

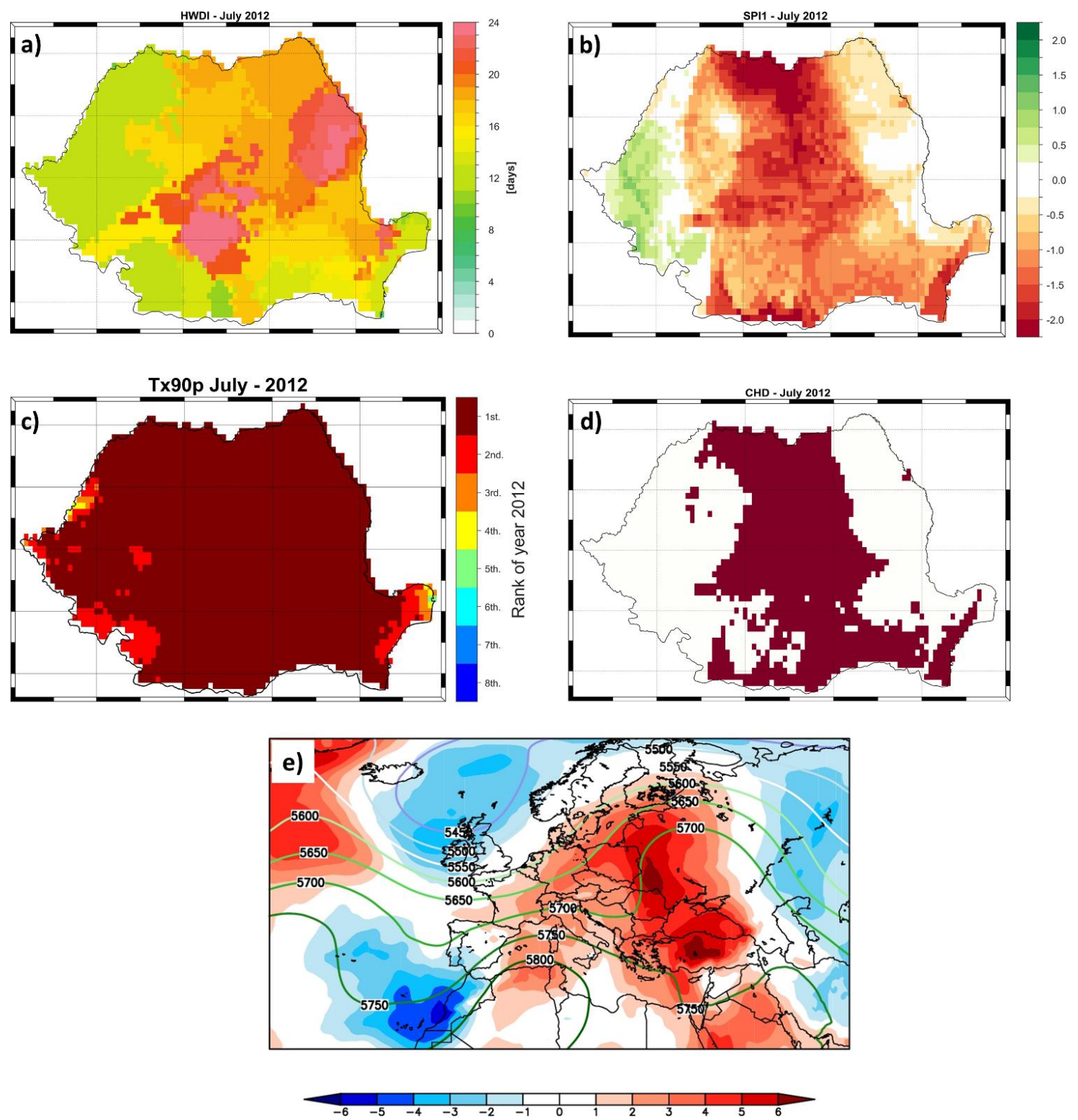

Figure 10. a) HWDI for July 2012; b) SPI1 for July 2012; c) Top-eight ranking of TX90p for July 2012 (1st means the, hottest (Tx90p) since 1950, 2nd signifies the second hottest, etc., and all ranks $>8$ are shown in white); d) CHD for June 2012 (the dark red color indicates the grid points affected by a CHD) and e) daily Z500 (contour lines) and TT850 anomalies (shaded colors) averaged over the period $25-30.07 .2012$.

Units: a) days/month; d) Z500 (m) and TT850 $\left({ }^{\circ} \mathrm{C}\right)$. For d) the analyzed period is 1950-2020. 

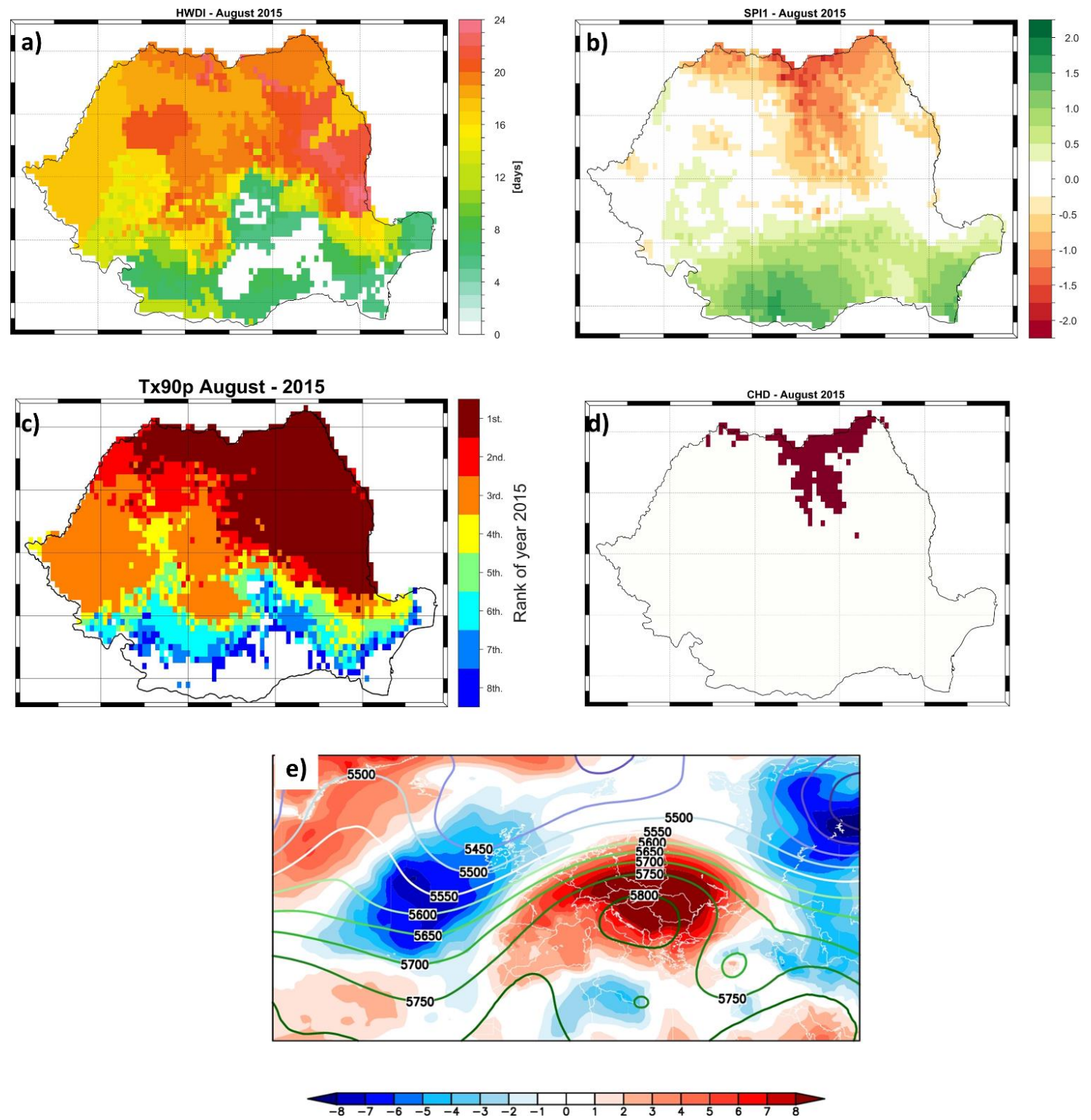

Figure 11. a) HWDI for August 2015; b) SPI1 for August 2015; c) Top-eight ranking of TX90p for August 2015 (1st means the, hottest (Tx90p) since 1950, 2nd signifies the second hottest, etc., and all ranks $>8$ are shown in white); d) CHD for August 2015 (the dark red color indicates the grid points affected by a CHD) and e) daily Z500 (contour lines) and TT850 anomalies (shaded colors) averaged over the period 28 - 31.08.2015. 

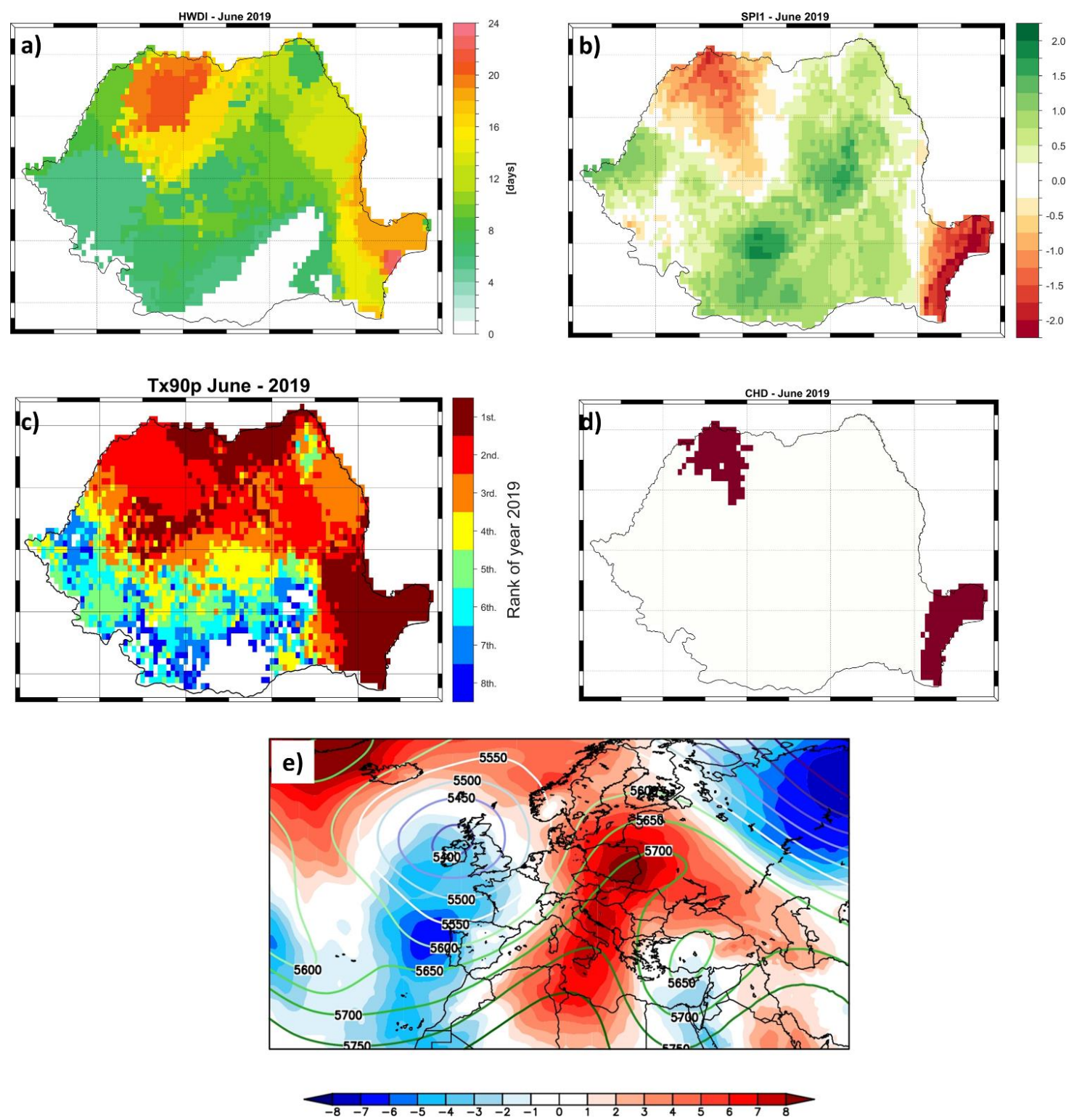

Figure 12. a) HWDI for June 2019; b) SPI1 for June 2019; c) Top-eight ranking of TX90p for June 2019 (1st means the, hottest (Tx90p) since 1950, 2nd signifies the second hottest, etc., and all ranks $>8$ are shown in white); d) CHD for June 2019 (the dark red color indicates the grid points affected by a CHD) and e) daily Z500 (contour lines) and TT850 anomalies (shaded colors) averaged over the period $10-14.06 .2019$.

Units: a) days/month; d) Z500 (m) and TT850 $\left({ }^{\circ} \mathrm{C}\right)$. For d) the analyzed period is $1950-2020$. 
a)
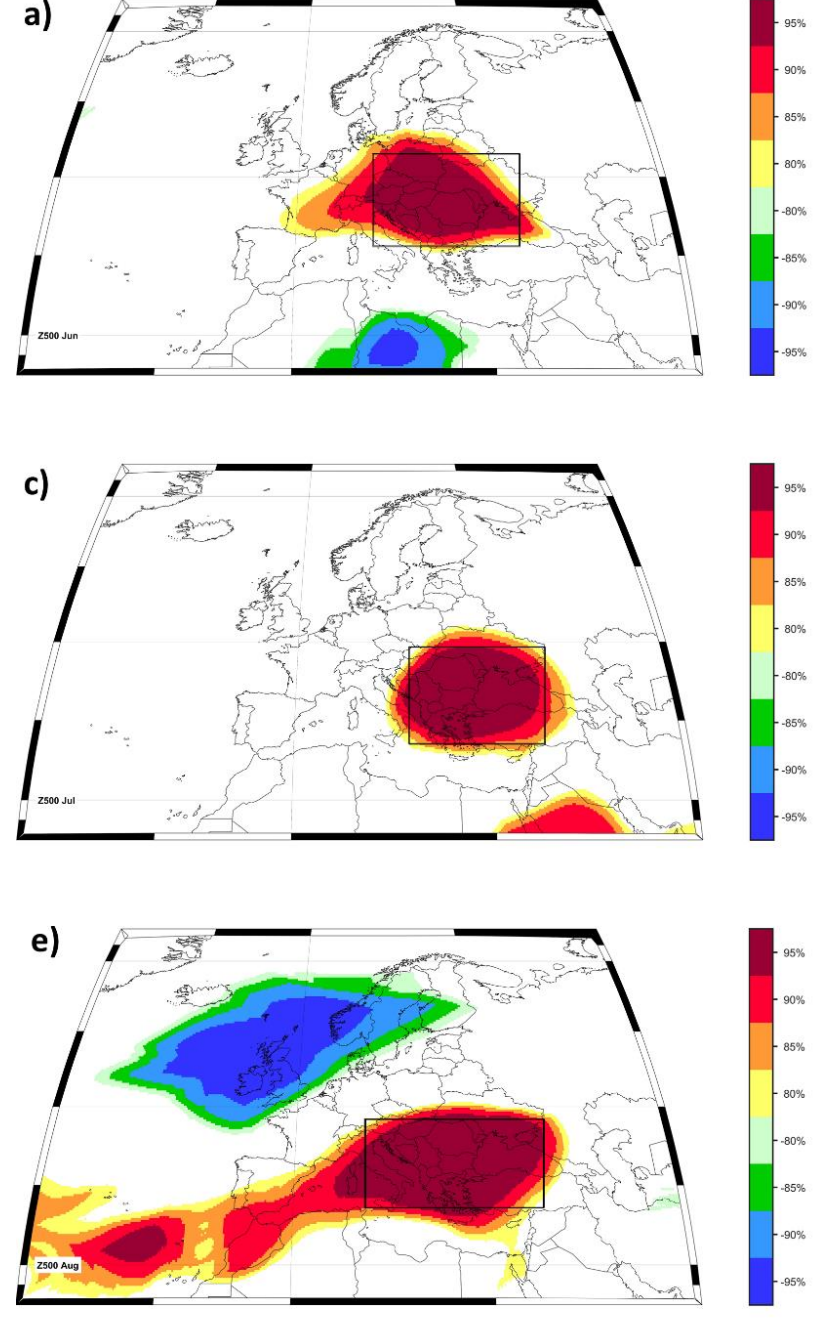
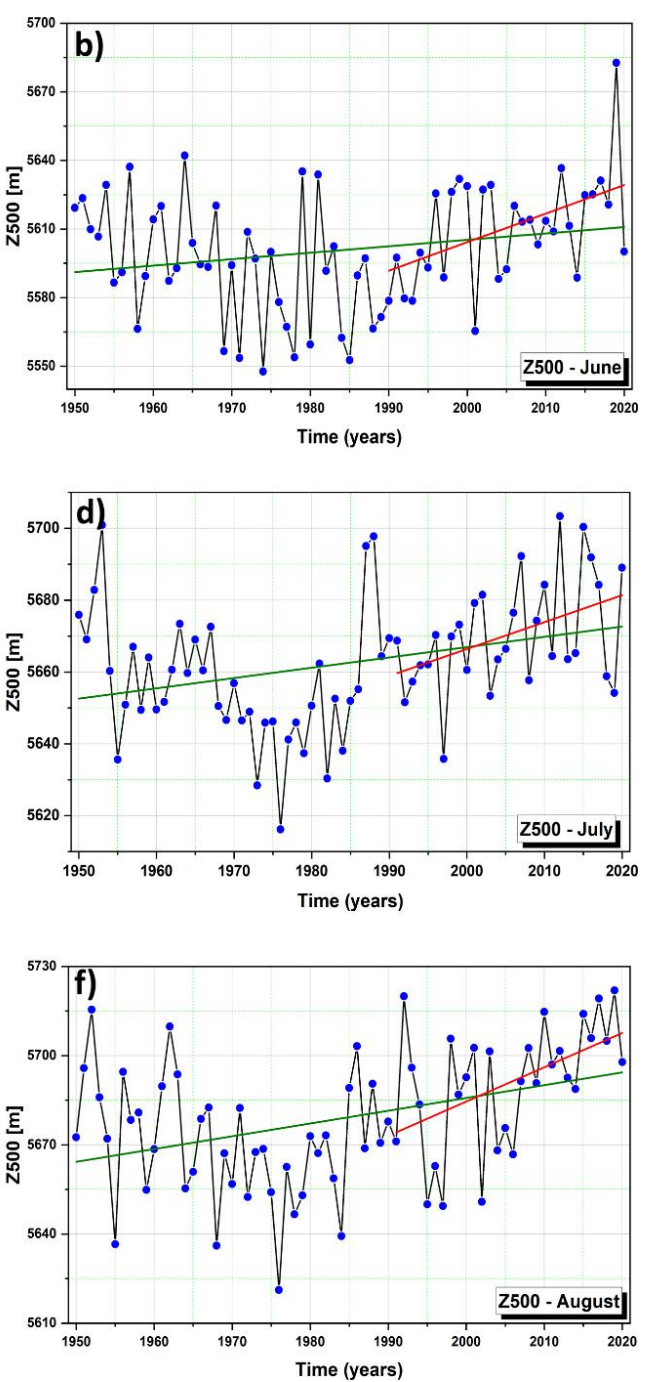

Figure 13. Stability maps of the correlation between monthly HWDI and monthly Z500 over the period $1950-2020$ (left column) and the time series of monthly Z500 averaged over the black box in a), c) and e).

a) Stability map for June; b) The time series of June Z500 averaged overt the black box in a);

b) Stability map for July; d) the time series of July Z500 averaged overt the black box in c);

e) Stability map for August and f) the time series of August Z500 averaged overt the black box in e).

In a), c) and e) the regions where the correlation is positive for at least $80 \%$ of the 31 -year windows are shaded with dark red $(95 \%)$, red $(90 \%)$, orange $(85 \%)$ and yellow $(80 \%)$. The corresponding regions where the correlation is significant, stable and negative, are shaded with dark blue (95\%), blue (90\%), green (85\%) and light green (80\%). The green (red) lines in b), d) and f) indicates the linear trend line of the monthly Z500 over the period $1950-2020(1990-2020)$. 